\title{
Membrane polarization in mixed-conducting ceramic fuel cells and electrolyzers
}

\author{
Huayang Zhu ${ }^{\mathrm{a}}$, Robert J. Kee $\mathrm{K}^{\mathrm{a}, *}$ \\ ${ }^{a}$ Department of Mechanical Engineering, Colorado School of Mines, Golden, CO 80401, \\ USA
}

\section{Abstract}

This paper focuses on modeling membrane-polarization processes within mixedconducting electrolyte membranes. Because a complete set of thermodynamic and transport properties is available, the electrolyte material used for the study is a yttrium-doped barium zirconate $\left(\mathrm{BaZr}_{0.9} \mathrm{Y}_{0.1} \mathrm{O}_{3-\delta}, \mathrm{BZY10}\right)$. Unlike Polymer Electrolyte Fuel Cells (PEMFC) and Solid-Oxide Fuel Cells (SOFC), the open-circuit voltage cannot be evaluated using gas-phase compositions alone. Using a Nernst-Planck-Poisson (NPP) model, an important aspect of the present paper is to develop the theory needed to evaluate opencircuit potential. Focusing on the mixed-conducting membrane alone, the present model neglects all activation and concentration overpotentials. The model is exercised in both fuel-cell and electrolyzer modes, revealing significantly different polarization behaviors. The model-based results show how the membrane polarization depends upon operating conditions, including temperature and gas-phase compositions.

Keywords:

\footnotetext{
*Corresponding author. Tel: (303) 273-3379.

Email address: rjkee@mines.edu (Robert J. Kee)
} 
Mixed conduction, Nernst-Planck-Poisson (NPP) model, BZY10, Fuel cell, Electrolyzer

\section{Introduction}

$2 \quad$ Protonic ceramic fuel cells (PCFCs) and electrolyzers (PCEC) are based 3 on ceramic, solid-electrolyte, membrane materials that exhibit good protonic 4 conductivity at intermediate temperatures $\left(400-700{ }^{\circ} \mathrm{C}\right)[1-4]$. Compared 5 to traditional solid-oxide fuel cells (SOFC), the intermediate operating tem-

perature of the PCFCs enables the use of inexpensive ferrite steel for interconnects, more reliable sealing, relatively rapid start-up, lower thermal stresses resulting from thermal-expansion mismatch of dissimilar materials, and negligible electrode sintering.

Doped-perovskite proton-conducting oxides have been widely investigated as PCFC electrolyte materials [1-3, 5]. Particularly, the acceptor-doped $\mathrm{BaCeO}_{3}, \mathrm{BaZrO}_{3}$, or mixed solid solutions of $\mathrm{BaCeO}_{3}$ and $\mathrm{BaZrO}_{3}$ have been demonstrated to have good proton conductivity at intermediate temperatures. However, although $\mathrm{BaCeO}_{3}$ has high conductivity, it is not useful for PCFC because it is chemically unstable in $\mathrm{H}_{2} \mathrm{O}$ and $\mathrm{CO}_{2}$ environments [6-8]. The acceptor-doped $\mathrm{BaZrO}_{3}$ materials (i.e, $\mathrm{BaZr}_{1-x} \mathrm{Y}_{x} \mathrm{O}_{3-\delta}$, BZY) demonstrate good chemical stability in $\mathrm{H}_{2} \mathrm{O}$ and $\mathrm{CO}_{2}$ environments, and are considered to be one of the most promising electrolyte materials for PCFCs [8-10].

Fig. 1 illustrates a protonic ceramic fuel cell (PCFC) and a protonic ceramic electrolysis cell (PCEC). Although the physical structure of the cells are identical, the difference between PCFC and PCEC are in the gas com- 


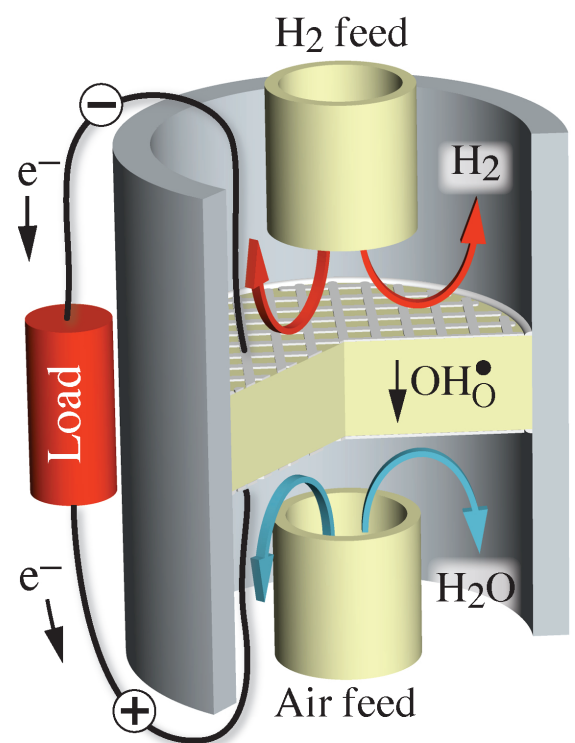

a) Fuel cell mode

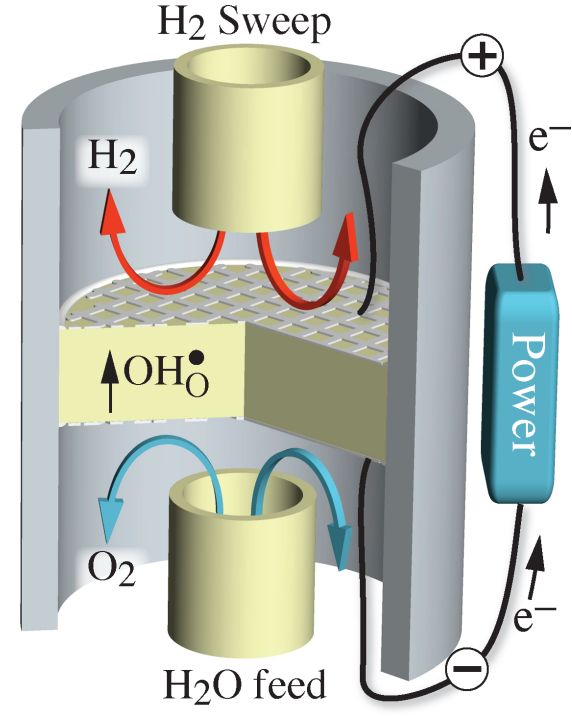

b) Electrolysis mode

Figure 1: Illustrations of a Protonic Ceramic Fuel Cell (PCFC) and a Protonic Ceramic Electrolysis Cell (PCEC), both in button-cell configurations. Note that the role of the anode (negative electrode) and cathode (positive electrode) are reversed between fuel-cell and electrolyzer operation.

position and the external electrical circuit. The fuel cell delivers electrical power by electrochemically oxidizing hydrogen. The electrolyzer uses electrical power to produce hydrogen from steam. In fuel-cell operation, hydrogen dissociatively adsorbs on the anode electro-catalyst surfaces. Adsorbed hydrogen on the membrane surface migrates toward the three-phase boundary (TPB) regions where electrons can be removed. Electrochemical incorporation chemistry delivers protons into the perovskite lattice. Protons are transported through the electrolyte toward the cathode where they react electrochemically with the oxygen to form water. At the same time, the electrochemical potentials drive the electrons from the anode through an external 
circuit to deliver power before returning back to the cathode. In electrolysis mode, the processes occur in the opposite direction, producing fuels from electricity.

The overall half-cell charge-transfer reaction for the oxidization of hydrogen to protons at the anode-electrolyte interfaces can be written globally as $[11-19]$

$$
\mathrm{H}_{2}(\mathrm{~g})+2 \mathrm{O}_{\mathrm{O}}^{\times}(\mathrm{el}) \rightleftharpoons 2 \mathrm{OH}_{\mathrm{O}}^{\bullet}(\mathrm{el})+2 \mathrm{e}^{\prime}(\mathrm{ed})
$$

The overall half-cell charge-transfer reaction of protons with oxygen to form water at three-phase boundaries of the cathode can be represented as [20-25]

$$
\mathrm{O}_{2}(\mathrm{~g})+4 \mathrm{OH}_{\mathrm{O}}^{\bullet}(\mathrm{el})+4 \mathrm{e}^{\prime}(\mathrm{ed}) \rightleftharpoons 2 \mathrm{H}_{2} \mathrm{O}(\mathrm{g})+4 \mathrm{O}_{\mathrm{O}}^{\times}(\mathrm{el})
$$

In this Kröger-Vink notation, the protons are designated as $\mathrm{OH}_{\mathrm{O}}^{\bullet}$. The parenthetical identifiers indicate gas-phase (g), electrode phase (ed), and electrolyte phase (el).

The protonic ceramics are usually not pure proton conductors. They are mixed ionic-electronic conductors (MIEC), which typically have two or three mobile charge-carrying defects. Taking BZY10 $\left(\mathrm{BaZr}_{0.9} \mathrm{Y}_{0.1} \mathrm{O}_{3-\delta}\right)$ as an example, there are three mobile charge-carrying defects-protons $\mathrm{OH}_{\mathrm{O}}^{\bullet}$, oxygen vacancies $\mathrm{V}_{\mathrm{O}}^{\bullet \bullet}$, and $\mathrm{O}$-site small polarons $\mathrm{O}_{\mathrm{O}}^{\bullet}[26]$. Each of these defects can participate in reactions at the BZY10 membrane-gas interface. Because of the multiple mobile charge-carrying defects within the electrolytes, there is usually a loss of potential to do electrical work (manifested as reduced open-circuit voltage). As discussed subsequently, mixed conduction within the membrane significantly influences the open-circuit potential, operating potential, and resistive losses through electrolyte membrane. 
Although BZY10 is chosen for the present study, the theory and computational approaches are the same as for other mixed-conducting electrolytes. The reason to chose BZY10 is that a complete set of thermodynamic and transport properties are available [26]. Tables 1 and 2 show the needed properties.

Early work by Riess $[27,28]$ introduced the notion of developing solidoxide fuel cells with mixed-conducting membranes. The underpinning theory in the Riess papers is similar to the approach in the present paper. However, the present paper develops a computational model, while the Riess made approximations that enabled analytic solutions. Also, Riess was concerned with materials that were dominantly oxygen-conducting membranes, not proton-conducting membranes.

\section{Cell Voltage}

The measurable cell voltage can be represented in terms of the electrochemical potential of the electrons within the electrodes as [29-31]

$$
E_{\text {cell }}=\Phi_{\mathrm{c}}-\Phi_{\mathrm{a}}=\frac{\tilde{\mu}_{\mathrm{e}^{\prime}}(\mathrm{c})-\tilde{\mu}_{\mathrm{e}^{\prime}}(\mathrm{a})}{F},
$$

where "c" and "a" represent cathode and anode. Assuming that all surface reactions are equilibrated, the charge-transfer reaction between the electrode and the mixed-conducting electrolyte can be expressed as

$$
\mathrm{O}_{\mathrm{O}}^{\times}(\mathrm{el})=\mathrm{O}_{\mathrm{O}}^{\bullet}(\mathrm{el})+\mathrm{e}^{\prime}(\mathrm{ed}),
$$

which is the combination of the electron-transfer reaction across the electrode-

BZY10 interface (i.e., Nil $\left.=\mathrm{e}^{\prime}(\mathrm{ed})+\mathrm{h} \bullet(\mathrm{el})\right)[32,33]$ and the definition of the O-site polaron (i.e., $\left.\mathrm{O}_{\mathrm{O}}^{\times}(\mathrm{el})+\mathrm{h} \bullet(\mathrm{el})=\mathrm{O}_{\mathrm{O}}^{\bullet}(\mathrm{el})\right)[26]$. 
At the anode-electrolyte interface, an activation overpotential $\eta_{\mathrm{a}}$ can be formally defined as

$$
\eta_{\mathrm{a}}=\left(\Phi_{\mathrm{a}}-\Phi_{\mathrm{e}, \mathrm{a}}\right)-E_{\mathrm{a}}^{\mathrm{eq}}
$$

where $\Phi_{\mathrm{a}}$ is the electric potential within the (metallic) anode, $\Phi_{\mathrm{e}, \mathrm{a}}$ is the electrostatic potential of electrolyte at the anode-electrolyte interface, and $E_{\mathrm{a}}^{\mathrm{eq}}=\Phi_{\mathrm{a}}^{\mathrm{eq}}-\Phi_{\mathrm{e}, \mathrm{a}}^{\mathrm{eq}}$ is the equilibrium electric potential difference between the anode and the electrolyte. Similarly, the activation overpotential at the cathode-electrolyte interface $\eta_{\mathrm{c}}$ can be formally defined as

$$
\eta_{\mathrm{c}}=\left(\Phi_{\mathrm{c}}-\Phi_{\mathrm{e}, \mathrm{c}}\right)-E_{\mathrm{c}}^{\mathrm{eq}}
$$

where $\Phi_{\mathrm{c}}$ is the electric potential within the cathode, $\Phi_{\mathrm{e}, \mathrm{c}}$ is the electrostatic potential of electrolyte at the cathode-electrolyte interface, and $E_{\mathrm{c}}^{\mathrm{eq}}=\Phi_{\mathrm{c}}^{\mathrm{eq}}-$ $\Phi_{\mathrm{e}, \mathrm{c}}^{\mathrm{eq}}$ is the equilibrium electric potential difference between the cathode and the electrolyte. The equilibrium electric-potential differences (e.g., $E_{\mathrm{c}}^{\mathrm{eq}}$ and $E_{\mathrm{a}}^{\mathrm{eq}}$ ) describe the electric-potential difference at which Eq. 4 proceeds equally in the forward and reverse directions, but with no net charge transfer.

At equilibrium, and considering Eq. 4, the charge-transfer processes between the electrodes and electrolyte membrane can be written in terms of electrochemical potentials $\tilde{\mu}_{k}$ as

$$
\tilde{\mu}_{\mathrm{O}_{\mathrm{O}}^{\times}(\mathrm{el})}=\tilde{\mu}_{\mathrm{O}} \mathbf{O}^{(\mathrm{el})}+\tilde{\mu}_{\mathrm{e}^{\prime}(\mathrm{ed})},
$$

where

$$
\tilde{\mu}_{\mathrm{O}_{\mathrm{O}}(\mathrm{el})}=\mu_{\mathrm{O}}^{\circ}(\mathrm{el})+R T \ln \left[\mathrm{O}_{\mathrm{O}}^{\bullet}(\mathrm{el})\right]+F \Phi_{\mathrm{el}}
$$

and

$$
\tilde{\mu}_{\mathrm{O}_{\mathrm{O}}^{\times}(\mathrm{el})}=\mu_{\mathrm{O}_{\mathrm{O}}^{\times}(\mathrm{el})}^{\circ}+R T \ln \left[\mathrm{O}_{\mathrm{O}}^{\times}(\mathrm{el})\right] .
$$


In these expressions, the standard-state chemical potentials are written as $\mu_{k}^{\circ}$ and the defect concentrations are written as $\left[X_{k}\right]$. The equilibrium electricpotential difference between the electrode and the electrolyte can be represented as

$$
E^{\mathrm{eq}}=\Phi_{\mathrm{ed}}^{\mathrm{eq}}-\Phi_{\mathrm{el}}^{\mathrm{eq}}=\frac{\mu_{\mathrm{O}_{\mathrm{O}}(\mathrm{el})}^{\circ}-\mu_{\mathrm{O}_{\mathrm{O}}^{\times}(\mathrm{el})}^{\circ}}{F}+\frac{R T}{F} \ln \frac{\left[\mathrm{O}_{\mathrm{O}}^{\bullet}(\mathrm{el})\right]}{\left[\mathrm{O}_{\mathrm{O}}^{\times}(\mathrm{el})\right]} .
$$

The cell operating potential $E_{\text {cell }}$ can be expressed as

$$
E_{\text {cell }}=\Phi_{\mathrm{c}}-\Phi_{\mathrm{a}}=E_{\mathrm{c}}^{\mathrm{eq}}-E_{\mathrm{a}}^{\mathrm{eq}}+\eta_{\mathrm{c}}-\eta_{\mathrm{a}}+\Phi_{\mathrm{e}, \mathrm{c}}-\Phi_{\mathrm{e}, \mathrm{a}}
$$

The present analysis is based on assuming perfect charge transfer in the sense that the activation overpotentials vanish, $\eta_{\mathrm{c}}=\eta_{\mathrm{a}}=0$. Thus, the cell potential $E_{\text {cell }}$ can be evaluated using the predicted defect concentrations and electrostatic potentials at the electrode interfaces as

$$
E_{\text {cell }}=\left(\Phi_{\mathrm{e}, \mathrm{c}}-\Phi_{\mathrm{e}, \mathrm{a}}\right)+\frac{R T}{F}\left(\ln \frac{\left[\mathrm{O}_{\mathrm{O}}^{\bullet}\right]_{\mathrm{e}, \mathrm{c}}}{\left[\mathrm{O}_{\mathrm{O}}^{\bullet}\right]_{\mathrm{e}, \mathrm{a}}}-\ln \frac{\left[\mathrm{O}_{\mathrm{O}}^{\times}\right]_{\mathrm{e}, \mathrm{c}}}{\left[\mathrm{O}_{\mathrm{O}}^{\times}\right]_{\mathrm{e}, \mathrm{a}}}\right) .
$$

The open-circuit potential may also be evaluated from Eq. 12. As discussed subsequently, with mixed conductors, $\Delta \Phi_{\mathrm{e}}=\left(\Phi_{\mathrm{e}, \mathrm{c}}-\Phi_{\mathrm{e}, \mathrm{a}}\right)$ does not vanish at open circuit.

Unfortunately, the electrostatic-potential difference within the mixedconducting electrolyte membrane $\Delta \Phi_{\mathrm{e}}=\Phi_{\mathrm{e}, \mathrm{c}}-\Phi_{\mathrm{e}, \mathrm{a}}$ cannot be measured. That is to say, as soon as electrodes are attached to measure the potentials, then the measurement represents the electrode potentials, not the desired internal electrostatic potentials within the electrolyte. However, the internal electrostatic potential can be predicted by solving the defect transport equations (i.e., the Nernst-Planck-Poisson, NPP, problem) [26, 31, 34]. The equilibrium defect concentrations at the electrode-electrolyte interfaces can 
Table 1: Thermodynamics for defect reactions

\begin{tabular}{lccc}
\hline Reactions & $\begin{array}{c}\Delta H^{\circ} \\
\left(\mathrm{kJ} \mathrm{mol}^{-1}\right)\end{array}$ & $\begin{array}{c}\Delta S^{\circ} \\
\left(\mathrm{J} \mathrm{mol}^{-1} \mathrm{~K}^{-1}\right)\end{array}$ & \\
\hline$\frac{1}{2} \mathrm{H}_{2}+\mathrm{O}_{\mathrm{O}}^{\bullet} \rightleftharpoons \mathrm{OH}_{\mathrm{O}}^{\bullet}$ & -146.01 & -0.89 & $2.56 \times 10^{+07}$ \\
$\frac{1}{2} \mathrm{O}_{2}+\mathrm{O}_{\mathrm{O}}^{\times}+\mathrm{V}_{\mathrm{O}}^{\bullet \bullet} \rightleftharpoons 2 \mathrm{O}_{\mathrm{O}}^{\bullet}$ & -36.08 & -125.48 & $1.94 \times 10^{-05}$ \\
$\mathrm{H}_{2} \mathrm{O}+\mathrm{V}_{\mathrm{O}}^{\bullet \bullet}+\mathrm{O}_{\mathrm{O}}^{\times} \rightleftharpoons 2 \mathrm{OH}_{\mathrm{O}}^{\bullet}$ & -80.00 & -71.78 & $2.16 \times 10^{+00}$ \\
$\mathrm{H}_{2}+\frac{1}{2} \mathrm{O}_{2} \rightleftharpoons \mathrm{H}_{2} \mathrm{O}$ & -248.11 & -55.48 & $5.87 \times 10^{+09}$ \\
\hline
\end{tabular}

Table 2: Charged-defect diffusion coefficients, $D_{k}=D_{k}^{\circ} \exp \left(-E_{k} / R T\right)$

\begin{tabular}{ccccc} 
& $\begin{array}{c}D_{k}^{\circ} \\
\left(\mathrm{m}^{2} \mathrm{~s}^{-1}\right)\end{array}$ & $\begin{array}{c}E_{k} \\
\left(\mathrm{~kJ} \mathrm{~mol}^{-1}\right)\end{array}$ & $\begin{array}{c}D_{k}\left(600{ }^{\circ} \mathrm{C}\right) \\
\left(\mathrm{m}^{2} \mathrm{~s}^{-1}\right)\end{array}$ & $\begin{array}{c}D_{k}\left(800{ }^{\circ} \mathrm{C}\right) \\
\left(\mathrm{m}^{2} \mathrm{~s}^{-1}\right)\end{array}$ \\
\hline $\mathrm{OH}_{\mathrm{O}}^{\bullet}$ & $9.39 \times 10^{-9}$ & 35.09 & $7.46 \times 10^{-11}$ & $1.84 \times 10^{-10}$ \\
$\mathrm{~V}_{\mathrm{O}}^{\bullet \bullet}$ & $1.30 \times 10^{-8}$ & 67.00 & $1.28 \times 10^{-12}$ & $7.12 \times 10^{-12}$ \\
$\mathrm{O}_{\mathrm{O}}^{\bullet}$ & $1.70 \times 10^{-3}$ & 86.00 & $1.22 \times 10^{-08}$ & $1.11 \times 10^{-07}$ \\
\hline
\end{tabular}

114 be evaluated assuming that the defect reactions at the surfaces are equili115 brated.

\section{Defect chemistry}

\subsection{Equilibrium defect reactions}

Three mobile charge-carrying defects (protons $\mathrm{OH}_{\mathrm{O}}^{\bullet}$, oxygen vacancies $\mathrm{V}_{\mathrm{O}}^{\bullet \bullet}$, and $\mathrm{O}$-site polarons $\mathrm{O}_{\mathrm{O}}^{\bullet}$ ) are involved in the defect reactions at the BZY10 ceramic-gas interface [26]. The incorporation reactions may be written as

$$
\begin{gathered}
\frac{1}{2} \mathrm{H}_{2}+\mathrm{O}_{\mathrm{O}}^{\bullet} \rightleftharpoons \mathrm{OH}_{\mathrm{O}}^{\bullet}, \\
\frac{1}{2} \mathrm{O}_{2}+\mathrm{O}_{\mathrm{O}}^{\times}+\mathrm{V}_{\mathrm{O}}^{\bullet \bullet} \rightleftharpoons 2 \mathrm{O}_{\mathrm{O}}^{\bullet},
\end{gathered}
$$




$$
\mathrm{H}_{2} \mathrm{O}+\mathrm{V}_{\mathrm{O}}^{\bullet \bullet}+\mathrm{O}_{\mathrm{O}}^{\times} \rightleftharpoons 2 \mathrm{OH}_{\mathrm{O}}^{\bullet} .
$$

125

126

${ }_{135} \Delta H^{\circ}-T \Delta S^{\circ}$ as

$$
K_{p}=\exp \left(-\frac{\Delta G^{\circ}}{R T}\right)=\exp \left(\frac{\Delta S^{\circ}}{R}\right) \exp \left(-\frac{\Delta H^{\circ}}{R T}\right) .
$$

$$
K_{p, \mathrm{H}_{2} \mathrm{O}}=\frac{\left[\mathrm{OH}_{\mathrm{O}}^{\bullet}\right]_{\mathrm{L}}^{2}}{p_{\mathrm{H}_{2} \mathrm{O}}\left[\mathrm{O}_{\mathrm{O}}^{\times}\right]_{\mathrm{L}}\left[\mathrm{V}_{\mathrm{O}}^{\bullet \bullet}\right]_{\mathrm{L}}} \text {. }
$$

The formula-unit concentrations $\left[X_{k}\right]_{\mathrm{L}}$ are related to the molar concentrations $\left[X_{k}\right]$ via the molar volume $V_{\mathrm{m}}$ as $\left[X_{k}\right]_{\mathrm{L}}=\left[X_{k}\right] V_{\mathrm{m}}$. For BZY10, the lattice molar volume is $V_{\mathrm{m}}=44.792 \times 10^{-6} \mathrm{~m}^{3} \mathrm{~mol}^{-1}$. The three equilibrium constants $K_{p, \mathrm{H}_{2}}, K_{p, \mathrm{O}_{2}}$ and $K_{p, \mathrm{H}_{2} \mathrm{O}}$ are not independent, but are coupled through the assumed gas-phase equilibrium constant $K_{p, \mathrm{G}}$ as

$$
K_{p, \mathrm{H}_{2}}^{2} K_{p, \mathrm{O}_{2}}=K_{p, \mathrm{H}_{2} \mathrm{O}} K_{p, \mathrm{G}}
$$

Here the gas phase is presumed to be in equilibrium according to

$$
\mathrm{H}_{2}+\frac{1}{2} \mathrm{O}_{2} \rightleftharpoons \mathrm{H}_{2} \mathrm{O}
$$

with $K_{p, \mathrm{G}}$ being the equilibrium constant. The equilibrium constants can be evaluated from the Gibbs free energy change for the reactions $\Delta G^{\circ}=$

Table 1 provides the needed thermodynamic properties for BZY10. 


\subsection{Site and eletroneutrality constraints}

On the surface and within the ceramic membrane, site constraints and electroneutrality must be preserved. The number of oxygen sites in a pervoskite lattice (per formula unit) must be maintained as 3. Thus,

$$
\left[\mathrm{V}_{\mathrm{O}}^{\bullet \bullet}\right]_{\mathrm{L}}+\left[\mathrm{OH}_{\mathrm{O}}^{\bullet}\right]_{\mathrm{L}}+\left[\mathrm{O}_{\mathrm{O}}^{\bullet}\right]_{\mathrm{L}}+\left[\mathrm{O}_{\mathrm{O}}^{\times}\right]_{\mathrm{L}}=3
$$

In this formulation, Eq. 22 is written to include the $\mathrm{O}$-site polaron $\left[\mathrm{O}_{\mathrm{O}}^{\bullet}\right]_{\mathrm{L}}$ in the site constraint [26]. Charge neutrality requires that

$$
2\left[\mathrm{~V}_{\mathrm{O}}^{\bullet \bullet}\right]_{\mathrm{L}}+\left[\mathrm{OH}_{\mathrm{O}}^{\bullet}\right]_{\mathrm{L}}+\left[\mathrm{O}_{\mathrm{O}}^{\bullet}\right]_{\mathrm{L}}-\left[\mathrm{Y}_{\mathrm{Zr}}^{\prime}\right]_{\mathrm{L}}=0
$$

Considering BZY10 $\left(\mathrm{BaZr}_{0.9} \mathrm{Y}_{0.1} \mathrm{O}_{3-\delta}\right)$, the doping concentration is $10 \%$, in which case $\left[\mathrm{Y}_{\mathrm{Zr}}^{\prime}\right]_{\mathrm{L}}=0.1$.

\subsection{Defect equilibrium concentrations}

The defect equilibrium concentrations (i.e., $\left[\mathrm{V}_{\mathrm{O}}^{\bullet \bullet}\right]_{\mathrm{L}},\left[\mathrm{OH}_{\mathrm{O}}^{\bullet}\right]_{\mathrm{L}},\left[\mathrm{O}_{\mathrm{O}}^{\bullet}\right]_{\mathrm{L}}$, and $\left.\left[\mathrm{O}_{\mathrm{O}}^{\times}\right]_{\mathrm{L}}\right)$ on the surface as functions of the gas-phase partial pressures (i.e., $p_{\mathrm{O}_{2}}, p_{\mathrm{H}_{2}}$, and $\left.p_{\mathrm{H}_{2} \mathrm{O}}\right)$ can be established by solving iteratively Eqs. 17, 18, 22, and 23. Note that Eq 16 is not used because Eqs. 16, 17, and 18 are not independent of each other (i.e., Eq. 19).

The iteration process is initiated by first estimating a value of $\left[\mathrm{V}_{\mathrm{O}}^{\bullet \bullet}\right]_{\mathrm{L}}$. Based on Eqs. 17, 18, and 23, the defect concentrations $\left[\mathrm{O}_{\mathrm{O}}^{\bullet}\right]_{\mathrm{L}}$ and $\left[\mathrm{OH}_{\mathrm{O}}^{\bullet}\right]_{\mathrm{L}}$ can be evaluated in terms of $\left[\mathrm{V}_{\mathrm{O}}^{\bullet \bullet}\right]_{\mathrm{L}}$ as

$$
\left[\mathrm{O}_{\mathrm{O}}^{\bullet}\right]_{\mathrm{L}}=\frac{\left[\mathrm{Y}_{\mathrm{Ce}, \mathrm{Zr}}^{\prime}\right]_{\mathrm{L}}-2\left[\mathrm{~V}_{\mathrm{O}}^{\bullet \bullet}\right]_{\mathrm{L}}}{1+\Theta}
$$

where

$$
\Theta=\frac{\left[\mathrm{OH}_{\mathrm{O}}^{\bullet}\right]_{\mathrm{L}}}{\left[\mathrm{O}_{\mathrm{O}}^{\bullet}\right]_{\mathrm{L}}}=\left[\frac{K_{p, \mathrm{H}_{2} \mathrm{O}}}{K_{p, \mathrm{O}_{2}}} \frac{p_{\mathrm{H}_{2} \mathrm{O}}}{p_{\mathrm{O}_{2}}^{1 / 2}}\right]^{1 / 2}
$$




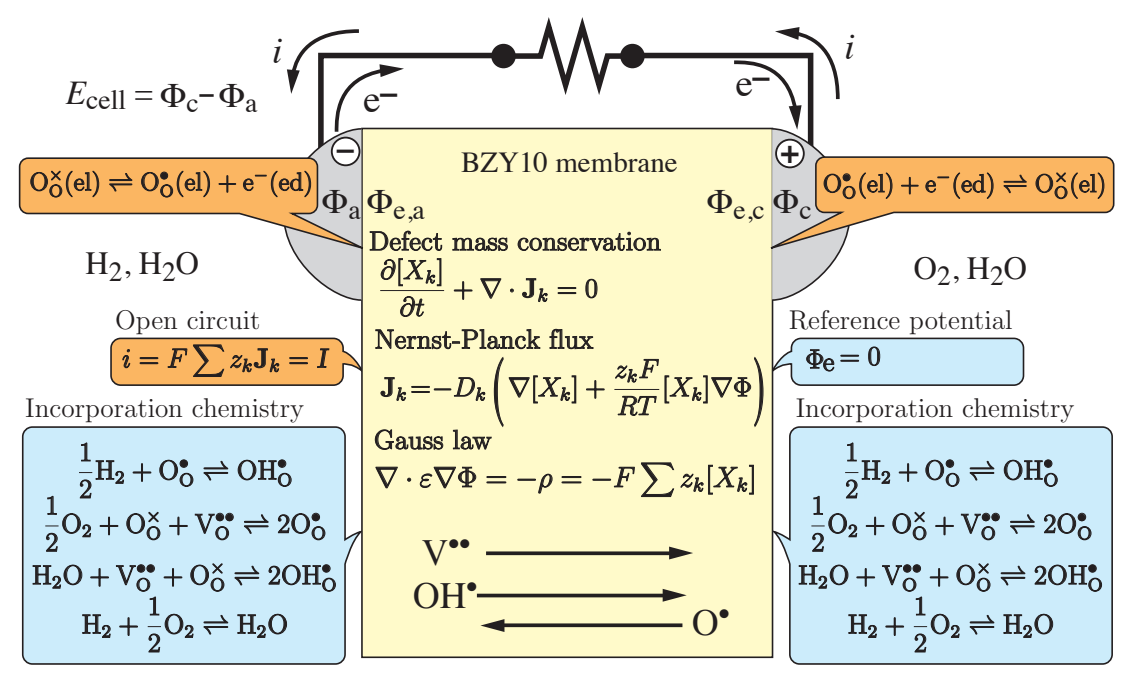

Figure 2: Summary of the NPP model in cartoon form. The electron and current directions are shown in fuel-cell mode.

Using Eq. 17, $\left[\mathrm{O}_{\mathrm{O}}^{\times}\right]_{\mathrm{L}}$ can be represented as

$$
\left[\mathrm{O}_{\mathrm{O}}^{\times}\right]_{\mathrm{L}}=\frac{\left[\mathrm{O}_{\mathrm{O}}^{\bullet}\right]_{\mathrm{L}}^{2}}{K_{p, \mathrm{O}_{2}} p_{\mathrm{O}_{2}}^{1 / 2}\left[\mathrm{~V}_{\mathrm{O}}^{\bullet \bullet}\right]_{\mathrm{L}}} .
$$

Finally, the oxygen site constraint (Eq. 22) is imposed. If all the equations above were to be explicitly substituted, the result would be one nonlinear equation with one unknown, $\left[\mathrm{V}_{\mathrm{O}}^{\bullet \bullet}\right]_{\mathrm{L}}$. Once $\left[\mathrm{V}_{\mathrm{O}}\right]_{\mathrm{L}}$ is determined, all the other defect concentrations follow easily from Eqs. 24, 25, and 26.

\section{Nernst-Planck-Poisson (NPP) membrane model}

The spatial and temporal variations of defect concentrations and the electrostatic potential through the perovskite membrane can be represented using the Nernst-Planck-Poisson model. The defect transport through the 
membrane is governed by conservation equations as

$$
\frac{\partial\left[X_{k}\right]}{\partial t}+\nabla \cdot \mathbf{J}_{k}=0 .
$$

Assuming dilute defect interactions, the defect transport fluxes $\mathbf{J}_{k}$ due to concentration gradients (diffusion) and electrostatic-potential gradients (migration) can be represented using a Nernst-Planck formulation as

$$
\mathbf{J}_{k}=-D_{k}\left(\nabla\left[X_{k}\right]+\frac{z_{k} F}{R T}\left[X_{k}\right] \nabla \Phi_{\mathrm{e}}\right),
$$

where $D_{k}$ are defect diffusion coefficients. Table 2 provides the needed diffusion coefficients for BZY10.

The local electrostatic potential $\Phi_{\mathrm{e}}$ can be related to the local charge density $\rho_{\mathrm{e}}$ through the Gauss law as

$$
\nabla \cdot\left(\varepsilon_{\mathrm{o}} \varepsilon_{\mathrm{r}} \nabla \Phi_{\mathrm{e}}\right)=-\rho_{\mathrm{e}}=-\sum_{k=1} z_{k} F\left[X_{k}\right]
$$

where $\varepsilon_{\mathrm{r}}$ and $\varepsilon_{\mathrm{o}}$ are the relative and vacuum permittivities, respectively. Alternatively, the Gauss law for the one-dimensional perovskite membrane can be equivalently replaced by the displacement-current equation as [35]

$$
\frac{\partial E}{\partial t}=\frac{1}{\varepsilon_{0} \varepsilon_{\mathrm{r}}}\left[I-\sum_{k} z_{k} F J_{k}\right],
$$

where $E=-\nabla \Phi_{\mathrm{e}}$ is the electric field, and $I$ is the external current density. Solving the Gauss equation is nearly equivalent to, but more general than, imposing strict electroneutrality (i.e., $\sum_{k=1}^{K} z_{k} F\left[X_{k}\right]=0$ ). Requiring strict electroneutrality leads to an implicit relationship (i.e., $\sum_{k} z_{k} F J_{k}=I$ ) from which the local electrostatic potential profiles can be determined [26, 34]. 
185

\subsection{Equilibrium gas-phase fluxes}

The transport fluxes of the ionic defect species manifest themselves as gasphase fluxes at the membrane-gas interfaces. Assuming equilibrium defect chemistry at the ceramic-gas interfaces, the gas-phase fluxes of $\mathrm{H}_{2} \mathrm{O}, \mathrm{H}_{2}$, and $\mathrm{O}_{2}$ can be evaluated as [34]

$$
\mathbf{J}_{\mathrm{H}_{2} \mathrm{O}}=\frac{\mathbf{J}_{\mathrm{OH}_{\mathrm{O}}}}{\left[2+\frac{2 p_{\mathrm{H}_{2}}}{p_{\mathrm{H}_{2} \mathrm{O}}}+\frac{p_{\mathrm{H}_{2}}}{2 p_{\mathrm{O}_{2}}}\right]}-\frac{\mathbf{J}_{\mathrm{V}_{\bullet}}}{\left[1+\frac{4 p_{\mathrm{O}_{2}}}{p_{\mathrm{H}_{2} \mathrm{O}}}+\frac{4 p_{\mathrm{O}_{2}}}{p_{\mathrm{H}_{2}}}\right]} .
$$

where $\mathbf{J}_{\mathrm{OH}_{\mathrm{O}}}$ and $\mathbf{J}_{\mathrm{V}_{\mathrm{O}}}$ are the molar fluxes of protons and oxygen vacancies at the membrane surfaces.

\subsection{Model summary}

Figure 2 summarizes the model in cartoon form. At the membrane surfaces, the defect incorporation chemistry is maintained at equilibrium with the local gas composition, which is also assumed to be equilibrated. This equilibrium, together with site constraints (Eq. 22) and charge neutrality (Eq. 23) serves to establish defect-concentration boundary conditions for the NPP problem, which at steady state is an elliptic boundary-value problem. Boundary conditions are also needed for the internal electrostatic potentials. At one surface (here the cathode), a reference potential is set arbitrarily to be $\Phi_{e, c}=0$. The other boundary is imposed implicitly in terms of the imposed current, $i=\sum z_{k} F J_{k}$. Implicit means that this boundary condition for the 
electrostatic potential $\Phi_{\mathrm{e}, \mathrm{a}}$ does not explicitly involve $\Phi_{\mathrm{e}, \mathrm{a}}$ itself. At open circuit, $i=0$. In fuel-cell mode $i>0$ and in electrolysis mode $i<0$. The NPP problem is solved computationally on a finite-volume mesh network. The present model is implemented in MATLAB using a method-of-lines approach.

\section{Results and discussions}

The present results are based on a BZY10 membrane electrolyte with a thickness of $20 \mu \mathrm{m}$. Equilibrium constants for the defect reactions can be evaluated using the thermodynamic properties listed in Table 1 . Table 2 lists needed defect transport parameters. Assuming ideal anodes and cathodes, all associated polarization losses (i.e., activation and concentration polarizations) are neglected. Although this is not a physically realistic assumption in practice, it does facilitate the specific focus on membrane polarization processes. The fuel-cell and electrolysis performance of the PCFC and PCEC cells are represented using polarization curves and the open-circuit potentials. The primary objective of the present study is to investigate the contributions of the mixed-conducting electrolyte membrane on the cell performance.

\subsection{Open-circuit potentials}

The open-circuit potential (Eq. 12) contains two parts: the electrostaticpotential difference across the electrolyte membrane $\Delta \Phi_{\mathrm{e}}=\Phi_{\mathrm{e}, \mathrm{c}}-\Phi_{\mathrm{e}, \mathrm{a}}$ and the electrostatic-potential difference $E_{\text {def }}$ associated with the defect concentration differences between the anode and cathode sides of the membrane,

$$
E_{\mathrm{def}}=\frac{R T}{F}\left(\ln \frac{\left[\mathrm{O}_{\mathrm{O}}^{\bullet}\right]_{\mathrm{e}, \mathrm{c}}}{\left[\mathrm{O}_{\mathrm{O}}^{\bullet}\right]_{\mathrm{e}, \mathrm{a}}}-\ln \frac{\left[\mathrm{O}_{\mathrm{O}}^{\times}\right]_{\mathrm{e}, \mathrm{c}}}{\left[\mathrm{O}_{\mathrm{O}}^{\times}\right]_{\mathrm{e}, \mathrm{a}}}\right) .
$$




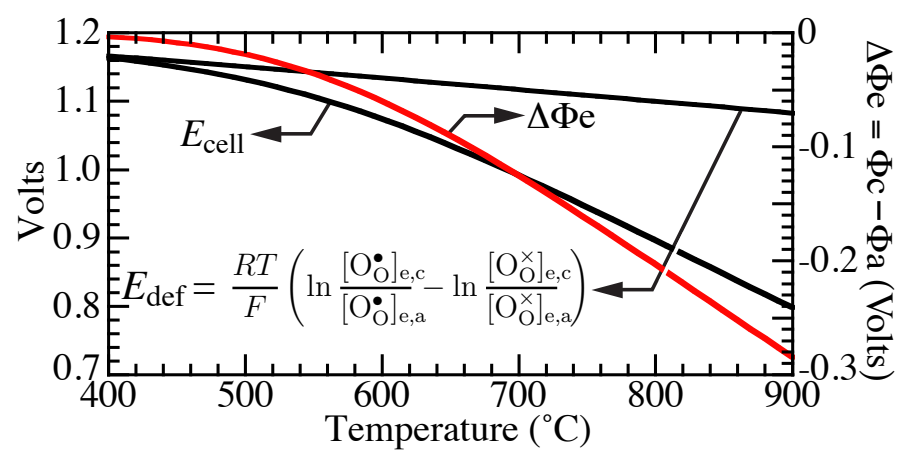

Figure 3: Open-circuit potentials as functions of the operating temperature. The gas composition is $97 \% \mathrm{H}_{2}$ and $3 \% \mathrm{H}_{2} \mathrm{O}$ on the anode side, and $20 \% \mathrm{O}_{2}, 3 \% \mathrm{H}_{2} \mathrm{O}$ and $77 \%$ $\mathrm{N}_{2}$ on the cathode side.

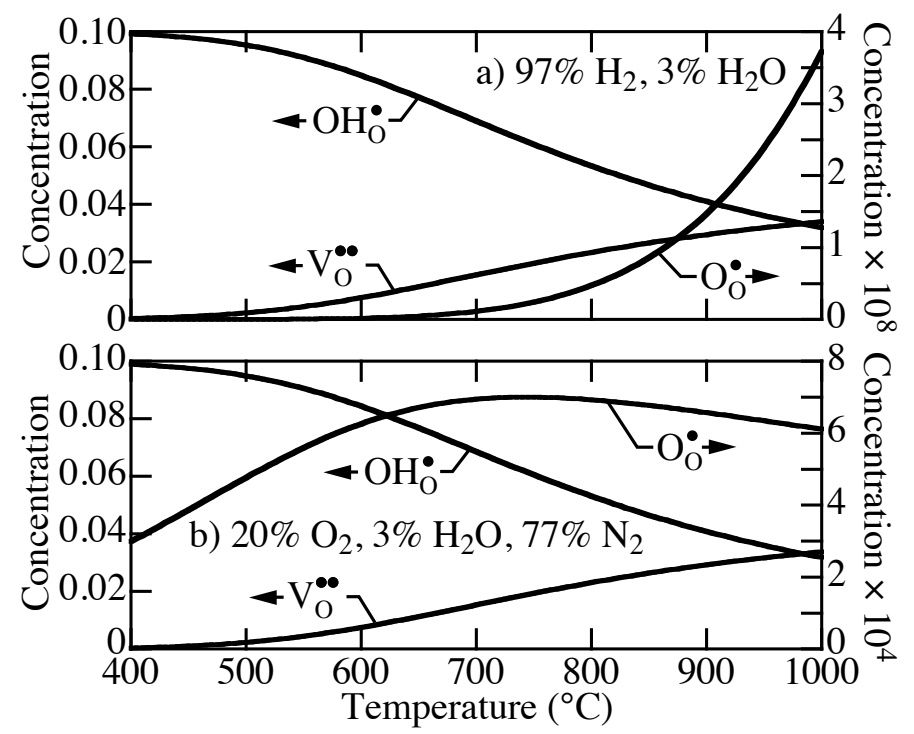

Figure 4: Equilibrium defect concentrations at the membrane-gas interfaces. Moist $\mathrm{H}_{2}$ is on one side of the membrane and moist air is on the other side.

The present model assumes that the temperature and the gas-phase compositions on both sides of the membrane are fixed. Thus, the equilibrium defect concentrations at the electrode-electrolyte interfaces are fixed based 
on the equilibrium defect chemistry. Therefore, $E_{\text {def }}$ depends only on the gas-phase compositions at the membrane surfaces. Furthermore, $\Delta \Phi_{\mathrm{e}}$ under open-circuit conditions also depends only on the gas-phase compositions. The fixed defect concentrations on the membrane surfaces are sufficient to determine the total electrostatic-potential difference across the electrolyte membrane. Although the electrostatic-potential gradient $\nabla \Phi_{\mathrm{e}}$ across the electrolyte membrane varies with the membrane thickness, the net electrostaticpotential difference $\Delta \Phi_{\mathrm{e}}$ does not depend on membrane thickness. Therefore, the open-circuit potential $E_{\text {cell }}=E_{\text {def }}+\Delta \Phi_{\mathrm{e}}$ does not change with the membrane thickness.

Figure 3 shows the variation of $E_{\text {def }}, \Delta \Phi_{\mathrm{e}}$, and $E_{\text {cell }}$ as functions of temperature. The gas compositions are taken to be $97 \% \mathrm{H}_{2}$ and $3 \% \mathrm{H}_{2} \mathrm{O}$ on the anode side, and $20 \% \mathrm{O}_{2}, 3 \% \mathrm{H}_{2} \mathrm{O}$ and $77 \% \mathrm{~N}_{2}$ on the cathode side, with net atmospheric pressure. As illustrated in Fig. 3, $E_{\text {def }}$ decreases as the temperature increases from 400 to $900{ }^{\circ} \mathrm{C}$. The electrostatic-potential loss term is approximately $\Delta \Phi_{\mathrm{e}} \approx 0.003 \mathrm{~V}$ at $400{ }^{\circ} \mathrm{C}$, and increases to approximately $\Delta \Phi_{\mathrm{e}} \approx 0.285 \mathrm{~V}$ at $900{ }^{\circ} \mathrm{C}$. Because of the decrease in $E_{\text {def }}$ and the significantly greater decrease in $\Delta \Phi_{\mathrm{e}}$ as the temperature increases, the open-circuit potential $E_{\text {cell }}$ drops greatly as the temperature increases.

The temperature-dependent variations in $E_{\text {cell }}$ can be explained by the effects of temperature on defect concentrations and the derivative effects on maintaing charge neutrality. Figure 4 shows illustrative equilibrium defect concentrations on both sides of the membrane as functions of temperature. In this case, one side of the membrane is maintained in a moist-hydrogen atmosphere and the other side is maintained in moist air. The proton con- 
centration decreases and the vacancy concentration increases as temperature increases, with the temperature dependencies being very similar on both sides of the membrane. Because the temperature dependencies are very similar, the proton gradient across the membrane depends only weakly on temperature. Compared to the protons, the polaron concentrations behave quite differently. First, the polaron concentrations are very much lower than the other defects (right-hand axis). Although the concentrations are low, the important observation is that the air-side polaron concentrations are very much greater (approximately four orders of magnitude) than the hydrogenside concentrations. That is, the air-side concentrations generally increase with increasing temperature, but the hydrogen-side polaron concentrations remain at essentially zero relative to the air side concentrations. Although there is a weak maximum at around $750{ }^{\circ} \mathrm{C}$, the effective polaron gradients generally increase as temperature increases.

With the equilibrium behaviors in mind, consider the Nernst-Planck defect fluxes in Eq. 28 that contain a diffusion term due to the concentration gradient and migration due to the electrostatic-potential gradient. Because the proton and vacancy concentrations on the fuel side are higher than those at the air side, the proton and vacancy diffuse from the fuel side toward the air side. The polarons diffuse from the air side toward the fuel side due to the higher polaron concentration on the air side. Under open-circuit conditions, the electric potential on the fuel side is higher than it is on the air side. Thus, the electrostatic-potential gradient (migration) enhances the Nernst-Planck fluxes of proton and vacancy from the fuel side toward the air side, but diminishes the polaron flux from the air side to the fuel side. Because the 


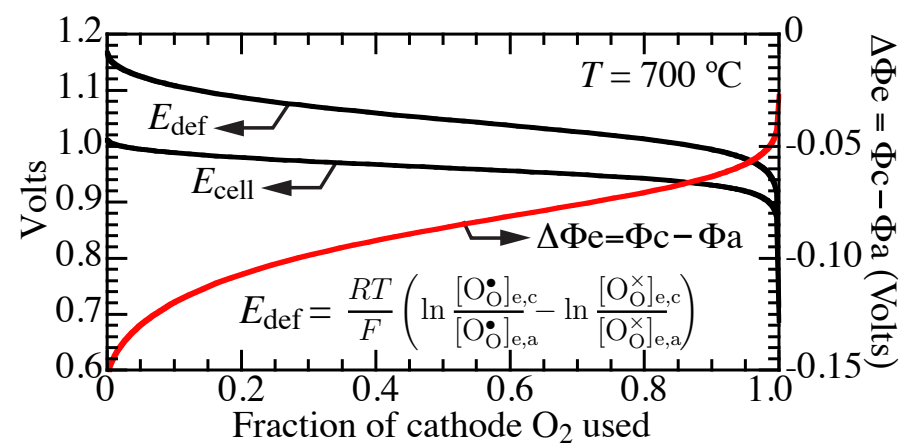

Figure 5: Open-circuit potentials as functions of the fraction of $\mathrm{O}_{2}$ consumption of the air stream. The operating temperature is $700{ }^{\circ} \mathrm{C}$. The gas composition is $97 \% \mathrm{H}_{2}$ and $3 \%$ $\mathrm{H}_{2} \mathrm{O}$ at the anode (fuel) side. The cathode (oxidizer) flow stream contains $21 \% \mathrm{O}_{2}$ and $79 \% \mathrm{~N}_{2}$ at zero $\mathrm{O}_{2}$ utilization, and $34.7 \% \mathrm{H}_{2} \mathrm{O}$ and $65.3 \% \mathrm{~N}_{2}$ at full $\mathrm{O}_{2}$ utilization.

polaron concentration gradients increase at higher temperature, the diffusion contribution for polaron transport flux increases. Additionally, because of higher mobility, the polaron flux is much higher than the proton and vacancy diffusion fluxes. To maintain charge neutrality (i.e., $\sum_{k} z_{k} F \mathbf{J}_{k}=0$ ), the magnitude of the internal electrostatic potential gradient must increase as the temperature increases. With higher electrostatic-potential gradients, the polaron diffusion flux can largely be reduced by the polaron migration flux. However, the proton and vacancy diffusion fluxes are enhanced by the migration fluxes. Therefore, the charge neutrality condition can be achieved.

Figure 5 shows the open-circuit potential variation as a function of $\mathrm{O}_{2}$ utilization in the cathode (oxidizer) flow stream. The operating temperature is $700{ }^{\circ} \mathrm{C}$. The gas composition at the anode (fuel) side is fixed $97 \% \mathrm{H}_{2}$ and $3 \% \mathrm{H}_{2} \mathrm{O}$. When the $\mathrm{O}_{2}$ utilization factor is zero, the cathode flow stream is air with $21 \% \mathrm{O}_{2}$ and $79 \% \mathrm{~N}_{2}$. Because one mole of $\mathrm{O}_{2}$ is consumed, 2 moles of $\mathrm{H}_{2} \mathrm{O}$ are produced, the cathode flow composition at 100\% $\mathrm{O}_{2}$ utilization 


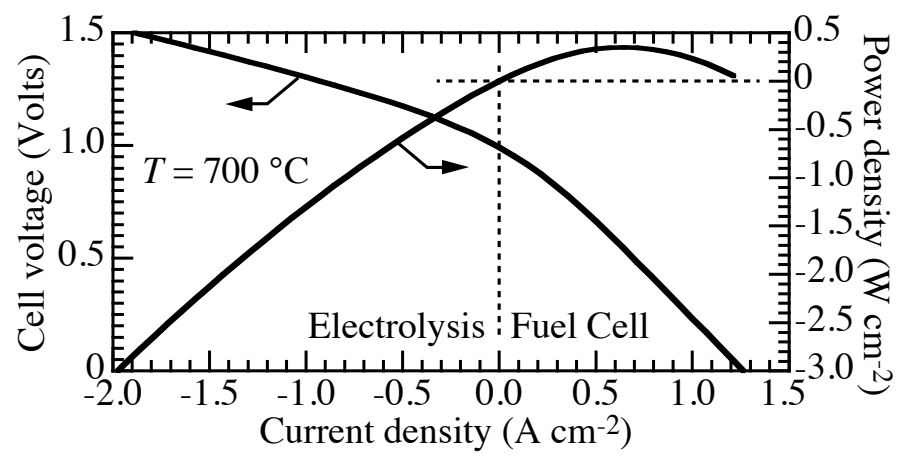

Figure 6: Polarization behavior at the nominal operating temperature of $700{ }^{\circ} \mathrm{C}$. The gas composition is $97 \% \mathrm{H}_{2}$ and $3 \% \mathrm{H}_{2} \mathrm{O}$ on the anode side, and $20 \% \mathrm{O}_{2}, 3 \% \mathrm{H}_{2} \mathrm{O}$ and $77 \%$ $\mathrm{N}_{2}$ on the cathode side.

becomes $34.7 \% \mathrm{H}_{2} \mathrm{O}$ and $65.3 \% \mathrm{~N}_{2}$. As illustrated in Fig. 5, $E_{\text {def }}$ decreases as $\mathrm{O}_{2}$ utilization factor increases due to less available $\mathrm{O}_{2}$ in the cathode flow stream. Meanwhile, the electrostatic-potential loss term $\Delta \Phi_{\mathrm{e}}$ becomes smaller when the oxidizer flow stream contains less $\mathrm{O}_{2}$ and more $\mathrm{H}_{2} \mathrm{O}$. The open-circuit potential $E_{\text {cell }}$ decreases as the $\mathrm{O}_{2}$ utilization factor increases.

\subsection{Fuel-cell operation}

For the sake of quantitative illustration, the nominal gas-phase composition for fuel-cell operation at the anode is fixed as $97 \% \mathrm{H}_{2}$ and $3 \% \mathrm{H}_{2} \mathrm{O}$, and the gas-phase species composition at the cathode is $20 \% \mathrm{O}_{2}, 3 \% \mathrm{H}_{2} \mathrm{O}$ and $77 \% \mathrm{~N}_{2}$. The nominal operating temperatures is $700{ }^{\circ} \mathrm{C}$ and the total gas-phase pressure is assumed to be atmospheric.

Figure 6 shows the cell potential and electric power as functions of the current density, spanning from the electrolysis mode to the fuel-cell mode. Under these conditions, the open-circuit potential is about $0.92 \mathrm{~V}$. When the cell is operating in the fuel-cell mode, the limiting current density is 


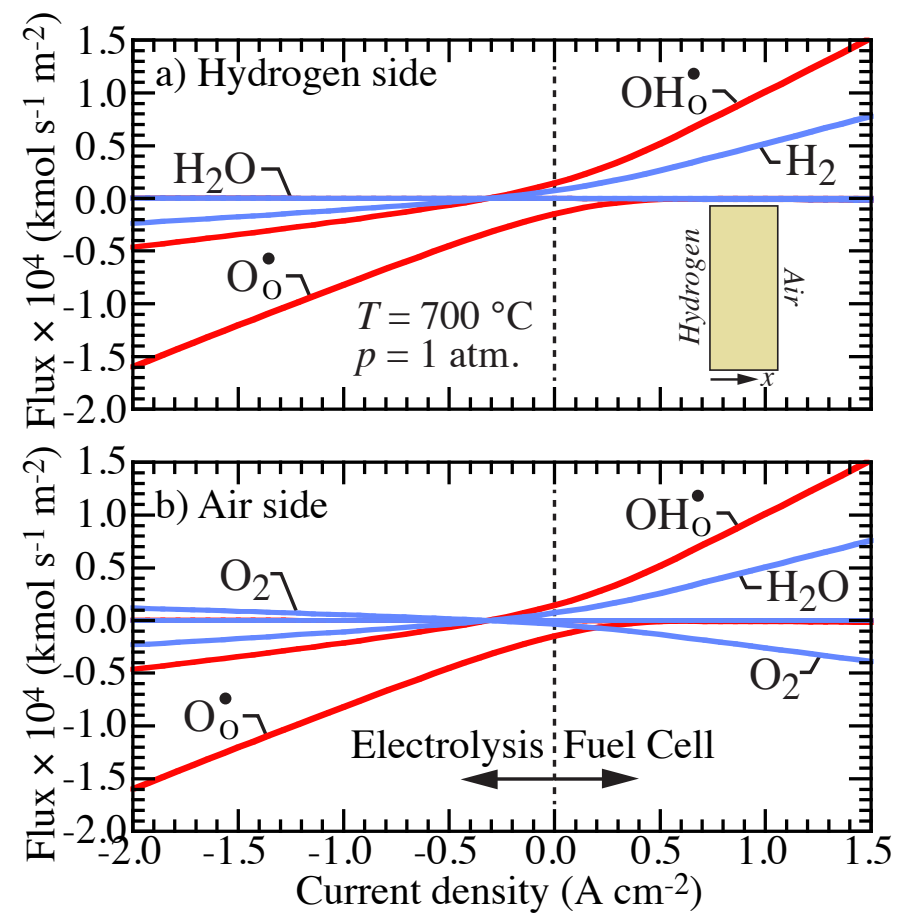

Figure 7: Fluxes of defects and gas-phase species at the electrode-electrolyte surfaces as functions of the current density. The operating temperature is $700{ }^{\circ} \mathrm{C}$. The gas composition is $97 \% \mathrm{H}_{2}$ and $3 \% \mathrm{H}_{2} \mathrm{O}$ at the anode side, and $20 \% \mathrm{O}_{2}, 3 \% \mathrm{H}_{2} \mathrm{O}$ and $77 \% \mathrm{~N}_{2}$ at the cathode side.

about $1.22 \mathrm{~A} \mathrm{~cm}^{-2}$ and the maximum power is about $0.35 \mathrm{~W} \mathrm{~cm}^{-2}$ when the current density is $0.63 \mathrm{~A} \mathrm{~cm}^{-2}$ and the cell potential is about $0.55 \mathrm{~V}$. In the electrolysis mode (negative current densities), higher cell potential is needed as the current density increases, and more electrical power is required to drive the system.

From Fig. 6 it is interesting to note that the membrane's area-specific resistance (i.e., slope of voltage versus current density) is significantly higher in fuel-cell mode than it is in electrolysis mode. As discussed subsequently, the 
reasons for these differences are related to the profiles of internal electrostatic potentials and defect concentrations under different operating conditions.

Fig. 7a shows the defect and gas-phase species fluxes at the hydrogen side of the membrane and Fig. $7 \mathrm{~b}$ shows the fluxes at the air side of the membrane. A positive flux means that the flux is in the direction from hydrogen side toward the air side. When the cell is operating in the fuel-cell mode, $\mathrm{H}_{2}$ is consumed and $\mathrm{OH}_{\mathrm{O}}^{\bullet}$ is produced at the anode-electrolyte interface, and a small amount of $\mathrm{H}_{2} \mathrm{O}$ is formed at the anode-electrolyte interface and released to the fuel compartment. The $\mathrm{OH}_{\mathrm{O}}^{\bullet}$ produced at the anode-electrolyte interface transports through the electrolyte membrane toward the cathode side. At the cathode-electrolyte interface, $\mathrm{OH}_{\mathrm{O}}^{\bullet}$ is electrochemically oxidized to produce $\mathrm{H}_{2} \mathrm{O}$ by consuming $\mathrm{O}_{2}$. When the cell is operating in the electrolysis mode, Fig. 7b shows $\mathrm{H}_{2} \mathrm{O}$ is consumed and $\mathrm{O}_{2}$ is produced at the air side. ${ }^{1}$ The $\mathrm{OH}_{\mathrm{O}}^{\bullet}$ produced at the air side of the membrane transports toward the hydrogen side. At the hydrogen side, $\mathrm{OH}_{\mathrm{O}}^{\bullet}$ is reduced and gas-phase $\mathrm{H}_{2}$ is formed and released.

Under open-circuit conditions (i.e., $i=0 \mathrm{~A} \mathrm{~cm}^{-2}$ ), it is interesting to note the directions and magnitudes of the defect transport. Protons are being transported toward the air side and O-site polarons are being transported toward the hydrogen side. There is also some vacancy transport, but under these conditions it is essentially negligible. At open circuit, the net charge

\footnotetext{
${ }^{1}$ Keep in mind that in electrolysis mode the roles of anode (negative electrode) and cathode (positive electrode) are reversed compared to fuel-cell operation (cf., Fig. 1).
} 
flux through the membrane must vanish. That is, at open circuit

$$
\sum z_{k} F \mathbf{J}_{k}=0
$$

where $z_{k}$ are the defect charges and $\mathbf{J}_{k}$ are the fluxes. However, the individual defect fluxes do not vanish at open circuit. This behavior is very different from a typical single-mobile-defect SOFC membrane (e.g., yttria-doped zirconia, YSZ) that is essentially a pure oxygen-ion conductor. The fact that mixed conductors permit defect transport at open-circuit is the reason that the reversible open-circuit potential is always less than that predicted by the Nernst equation [e.g., $\left.E_{\mathrm{rev}}=(R T / 4 F) \ln \left(p_{\mathrm{O}_{2}, \mathrm{c}} / p_{\mathrm{O}_{2}, \mathrm{a}}\right)\right]$ that applies for singleion conductors. In other words, the energy needed to support the internal defect transport diminishes the potential to do work that is associated with oxidation of the fuel.

Because mixed conducting membranes usually have electrical conductivity, it is often said that the loss of open-circuit potential is associated with a "leakage" current. In fact, this is a bit of a misnomer. There is no net electronic "leakage" through the membrane at open circuit in the sense that any current enters an external circuit. Rather, the loss of potential is associated with the energy needed to support the internal defect transport, while maintaining zero net charge flux.

Fig. 8 shows spatial profiles of the electrostatic potential and the defect concentrations through the electrolyte membrane at four different current densities: $-1.5,0.0,0.5$ and $1.2 \mathrm{~A} \mathrm{~cm}^{-2}$ (negative current density means electrolysis mode). The electrostatic potential at the air side is set to be zero as a reference. As illustrated in Fig. 8a, the electrostatic potential at the hydrogen side is higher than it is at the air side when operating in the fuel- 

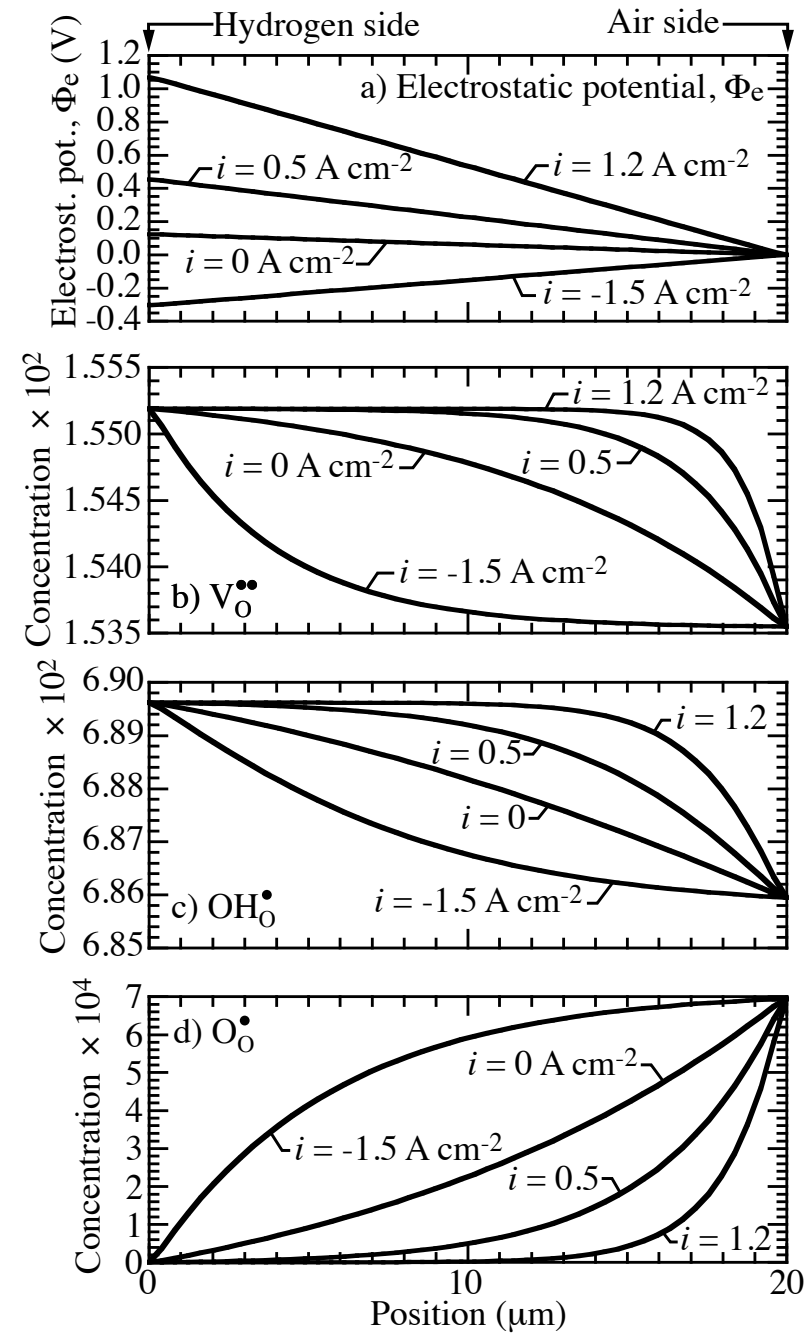

Figure 8: Profiles of electric potential and defect concentrations (formula unit) through the electrolyte membrane at four current densities: $-1.5,0.0,0.5$ and $1.2 \mathrm{~A} \mathrm{~cm}^{-2}$. The operating temperature is $700{ }^{\circ} \mathrm{C}$. The gas composition is $97 \% \mathrm{H}_{2}$ and $3 \% \mathrm{H}_{2} \mathrm{O}$ at the anode side (left), and $20 \% \mathrm{O}_{2}, 3 \% \mathrm{H}_{2} \mathrm{O}$ and $77 \% \mathrm{~N}_{2}$ at the cathode side (right).

cell mode (i.e., $i_{\mathrm{e}}=0.5$ and $1.2 \mathrm{~A} \mathrm{~cm}^{-2}$ ). The electrostatic potential gradient tends to drive all the positively charged mobile defects within the electrolyte membrane from the hydrogen side toward the air side. As the current density 
increases, the internal electrostatic potential gradient becomes larger, which drives the variation of defect concentrations closer to the air side. Hence the high concentration gradients near the air side of the membrane. Since both the fuel stream and air stream contain $3 \% \mathrm{H}_{2} \mathrm{O}$, the overall variations of the defect concentrations, except the polarons $\mathrm{O}_{\mathrm{O}}^{\bullet}$, change only slightly. As the current density increases, the slope of the electric potential becomes steeper, causing higher overpotential loss for the defect transport through the electrolyte membrane.

At open-circuit $(i=0)$, Fig. 8a shows an electrostatic-potential difference of approximately $0.125 \mathrm{~V}$ from the fuel side to the cathode. It is interesting to note that the electrostatic potential is greater at the fuel side than it is at the cathode side. This is possibly an unexpected result because the sign of the electrostatic-potential difference within the membrane is opposite from the sign of the electric-potential difference between the electrodes. That is to say, in fuel cell operation the electric potential of the cathode (air side, positive terminal) is greater than the electric potential of the anode (fuel side, negative terminal). Thus, it cannot be the case that the electric potentials are the same across the electrode-electrolyte interfaces. In models such as the present one, the vanishingly thin space-charge region at the electrode-electrolyte interfaces is modeled using a "jump" described in terms of activation overpotentials. Here, the activation overpotentials are assumed to vanish.

With increasingly high current densities in fuel-cell mode, the magnitude of the internal electrostatic-potential gradient become larger. Near limiting current in fuel-cell mode $\left(i=1.2 \mathrm{~A} \mathrm{~cm}^{-2}\right)$, the internal electrostatic-potential 
difference is nearly equivalent to the open-circuit potential (albiet, with opposite sign). In electrolysis mode $(i<0)$, the sign of the electrostatic-potential difference is opposite from that in fuel-cell mode. This behavior is discussed subsequently, when the gas-compositions are set to represent typical electrolysis operation.

Figures 8b-d show defect concentration profiles (lattice formula units) within the membrane at different current densities. It is evident that the defect concentration profiles depend greatly on the current density. At high current density in fuel-cell mode $(i>0)$, the profiles tend to shift toward the air side. In electrolysis mode, the profiles shift toward the fuel side. These behaviors are caused by the relatively complex interactions between the defect diffusion and migration as represented by the NPP model. The qualitatively different polarization mechanisms cause the differences in internal membrane polarization as evidenced in Fig. 6 when shifting from fuel-cell to electrolysis operation.

Figure 9a compares the cell potentials as functions of current density at four operating temperatures $\left(500,600,700\right.$ and $\left.800{ }^{\circ} \mathrm{C}\right)$. The current density spans from the electrolysis mode to fuel-cell mode, but the gas compositions are set for nominal fuel cell operation. Figure $9 \mathrm{~b}$ shows the corresponding variation of the power density as functions current density and temperature. As illustrated in Fig. 9, the cell potentials operating in fuel cell mode drop faster and less power is produced as the temperature decreases from 800 ${ }^{\circ} \mathrm{C}$ to $500{ }^{\circ} \mathrm{C}$. Under the electrolysis mode, higher cell potential and more electric power are needed to maintain the same operating current density as the temperature decreases. Figure 9a also shows that the open-circuit 

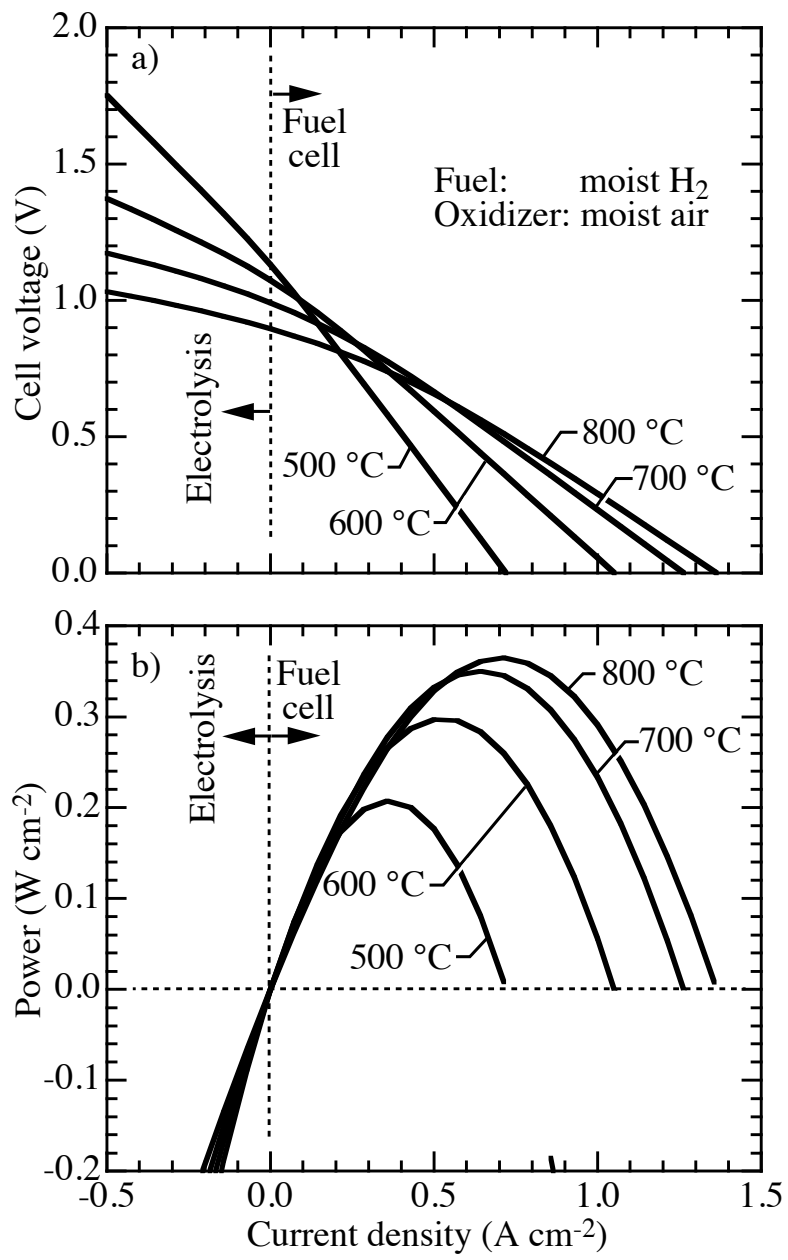

Figure 9: Comparison of the cell voltage and power density as functions of the current density at the four different operating temperatures: 500,600, 700, and $800{ }^{\circ} \mathrm{C}$. The gas composition is set to represent fuel-cell operation, with $97 \% \mathrm{H}_{2}$ and $3 \% \mathrm{H}_{2} \mathrm{O}$ on the fuel (anode) side and $20 \% \mathrm{O}_{2}, 3 \% \mathrm{H}_{2} \mathrm{O}$, and $77 \% \mathrm{~N}_{2}$ on the cathode (air) side. The total pressure is atmospheric.

410 potentials increase significantly as the temperature decreases. 

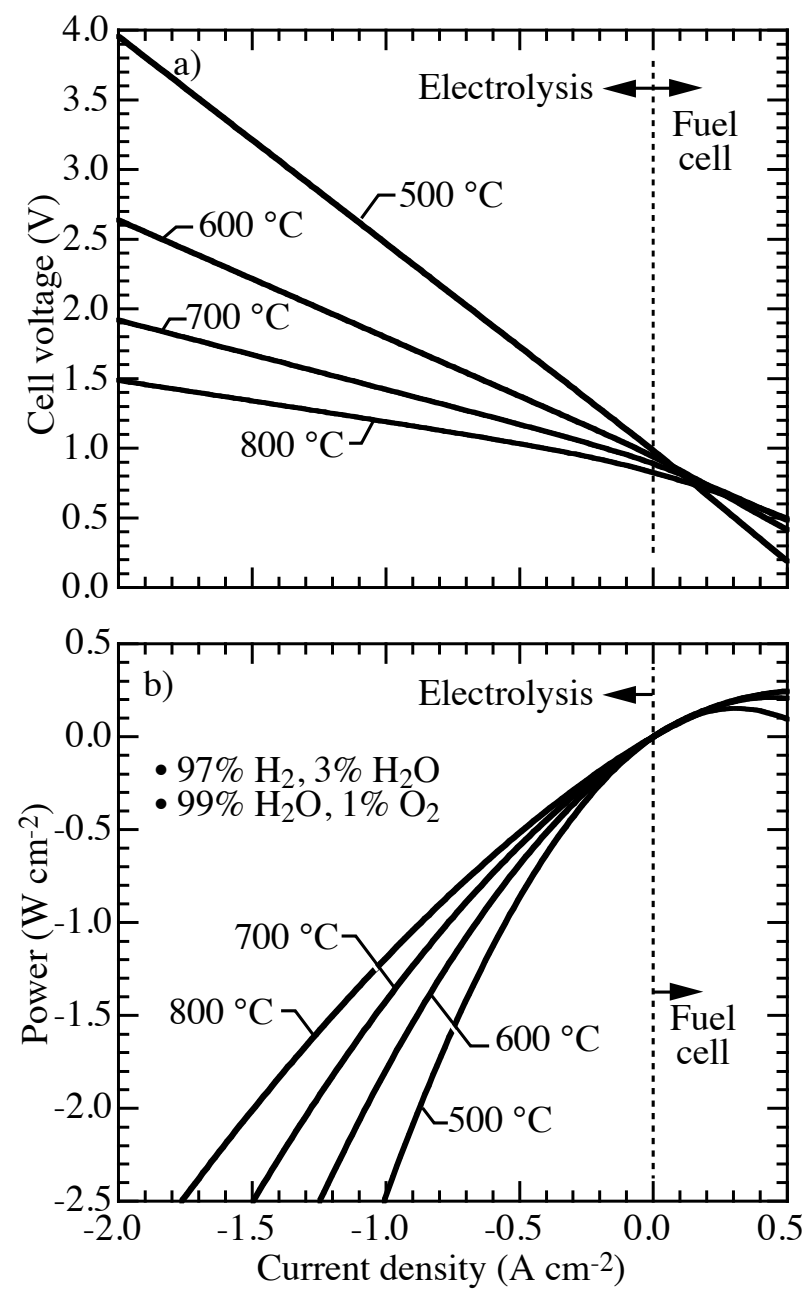

Figure 10: Comparison of the cell voltage and power density as functions of the current density at the four different operating temperatures: 500, 600, 700, and $800{ }^{\circ} \mathrm{C}$. The gas composition is set to represent electrolysis operation, with $97 \% \mathrm{H}_{2}$ and $3 \% \mathrm{H}_{2} \mathrm{O}$ on the cathode (positive electrode) side and $1 \% \mathrm{O}_{2}$ and $99 \% \mathrm{H}_{2} \mathrm{O}$ on the anode (negative electrode) side. The total pressure is atmospheric.

\subsection{Electrolysis operation}

The nominal gas-phase composition chosen for electrolysis operation is $97 \% \mathrm{H}_{2}$ and $3 \% \mathrm{H}_{2} \mathrm{O}$ at the cathode side (upper chamber, Fig. 1b), and $1 \%$ 


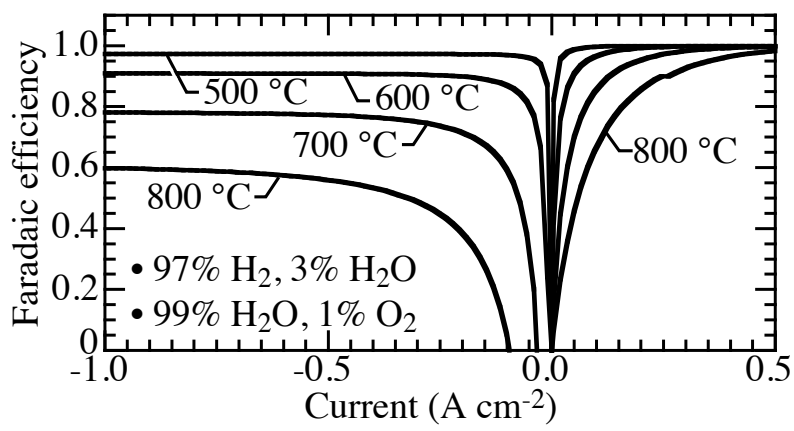

Figure 11: Faradaic efficiencies as function of current density. In electrolysis mode $(i<0)$ the Faradaic efficiency measures the $\mathrm{H}_{2}$ production efficiency relative to input current. In fuel-cell mode $(i>0)$ the Faradaic efficiency measures the electric-current production relative to $\mathrm{H}_{2}$ consumption rate. The gas composition is set to represent electrolysis operation, with $97 \% \mathrm{H}_{2}$ and $3 \% \mathrm{H}_{2} \mathrm{O}$ on the cathode (positive electrode) side and $1 \% \mathrm{O}_{2}$ and $99 \% \mathrm{H}_{2} \mathrm{O}$ on the anode (negative electrode) side. The total pressure is atmospheric.

$\mathrm{O}_{2}$ and $99 \% \mathrm{H}_{2} \mathrm{O}$ at the anode side (lower chamber, Fig. 1b). The operating conditions consider four temperatures $\left(500,600,700\right.$, and $800{ }^{\circ} \mathrm{C}$ ) and net atmospheric pressure.

Fig. 10 shows cell potential and electric power as functions of current density. Fig. 10a shows that the open-circuit potential decreases as the operating temperature increases (i.e., $E_{\text {cell }} \approx 0.98 \mathrm{~V}$ at $500{ }^{\circ} \mathrm{C}, E_{\text {cell }} \approx 0.94 \mathrm{~V}$ at $600{ }^{\circ} \mathrm{C}, E_{\text {cell }} \approx 0.89 \mathrm{~V}$ at $700{ }^{\circ} \mathrm{C}$, and $E_{\text {cell }} \approx 0.83 \mathrm{~V}$ at $800{ }^{\circ} \mathrm{C}$ ). As also seen from Fig. 9, higher operating cell potentials and more electric power are required for the cell to be operated in the electrolysis mode as the operating temperature is reduced from 800 to $500{ }^{\circ} \mathrm{C}$.

\subsubsection{Faradaic efficiency}

In part because of mixed-conduction behavior, ideal operation of PCFC and PCEC usually cannot be realized. In fuel-cell mode, the hydrogen flux 
leaving the hydrogen compartment may not be fully converted into the desired electric current. In electrolysis mode, the imposed electric current may not be fully converted to the desired $\mathrm{H}_{2}$ flux. The Faradaic efficiency can be defined to represent the conversion efficiency between the fuel consumption/production and the electric current. Faradaic efficiency in the electrolysis mode is defined to be the ratio of the $\mathrm{H}_{2}$ production flux and the imposed electric current density $I$ as

$$
\varepsilon_{\mathrm{H}_{2}, \mathrm{EC}}=\frac{2 F J_{\mathrm{H}_{2}}}{I}
$$

In fuel-cell mode, Faradaic efficiency is defined to be the ratio of the delivered external current density and the $\mathrm{H}_{2}$ consumption flux as

$$
\varepsilon_{\mathrm{H}_{2}, \mathrm{FC}}=\frac{I}{2 F J_{\mathrm{H}_{2}}} .
$$

Fig. 11 compares Faradaic efficiencies as functions of current density at four operating temperatures. For each temperature, the electrolysis-mode Faradaic efficiencies $\varepsilon_{\mathrm{H}_{2} \text {,EC }}$ achieve maximum asymptotic values at high current densities. These maximum Faradaic efficiencies increase significantly at lower temperatures, but never achieve unity. The Faradaic efficiencies decrease dramatically (even become negative) at low current densities near open-circuit operation.

The Faradaic efficiency in fuel-cell mode $\varepsilon_{\mathrm{H}_{2}, \mathrm{FC}}$ is zero at the open circuit, and then increases as the output current density increases, reaching maximum efficiencies very near unity at high current density. The maximum fuel-cell Faradaic efficiencies are higher than are the maximum electrolysis Faradaic efficiencies. The maximum $\varepsilon_{\mathrm{H}_{2}, \mathrm{EC}}$ is approximately 0.97 at $500{ }^{\circ} \mathrm{C}$, but drops to approximately 0.91 at $600{ }^{\circ} \mathrm{C}, 0.78$ at $700{ }^{\circ} \mathrm{C}$, and 0.61 at 
$800{ }^{\circ} \mathrm{C}$. Although the maximum $\varepsilon_{\mathrm{H}_{2}, \mathrm{EC}}$ at $500{ }^{\circ} \mathrm{C}$ is much higher than it is at $800{ }^{\circ} \mathrm{C}$, much higher operating cell potential, and thus higher power, are required to achieve the high Faradaic efficiencies (cf., Fig. 10). Thus, achieving high Faradaic efficiency alone does not necessarily lead to the best operating conditions for the cell.

\subsubsection{Profiles and fluxes}

Reduction in Faradaic efficiency is caused by electronic transport associated with the O-site polaron. Although the $\mathrm{O}_{\mathrm{O}}^{\bullet}$ transport is often unavoidable, the electronic transport demands energy that could otherwise be available to assist the production of desired products (electricity in PCFCs and $\mathrm{H}_{2}$ in PCEC). In other words, energy is required to drive the $\mathrm{O}_{\mathrm{O}}^{\bullet}$ through the resistive membrane material, but the $\mathrm{O}_{\mathrm{O}}^{\bullet}$ flux does not contribute directly to the desired product. The reasons for Faradaic losses can be explained and interpreted by studying defect profiles within the membrane and the associated defect fluxes.

With the gas compositions nominally set for electrolysis operation, Fig. 12 illustrates profiles of electric potentials and defect concentrations within the electrolyte membrane at four current densities: $-1.5,-0.5,0.0$, and $0.5 \mathrm{~A}$ $\mathrm{cm}^{-2}$. The operating temperature is fixed as $600{ }^{\circ} \mathrm{C}$. Fig. 13 shows the defect fluxes and gas-phase species fluxes at the membrane surfaces as functions of current density. For current densities of $i=0.0$ and $i=0.5 \mathrm{~A} \mathrm{~cm}^{-2}$ (i.e., open circuit and fuel-cell mode), Fig. 12 shows that the electrostatic potentials are higher on the hydrogen side than they are on the stream-oxygen side $\left(\Delta \Phi_{\mathrm{e}} \approx-0.019 \mathrm{~V}\right.$ at $i=0 \mathrm{~A} \mathrm{~cm}^{-2}$, and $\Delta \Phi_{\mathrm{e}} \approx-0.55 \mathrm{~V}$ at $i=0.5 \mathrm{~A}$ $\mathrm{cm}^{-2}$ ). The positively charged defects are driven toward the steam-oxygen 

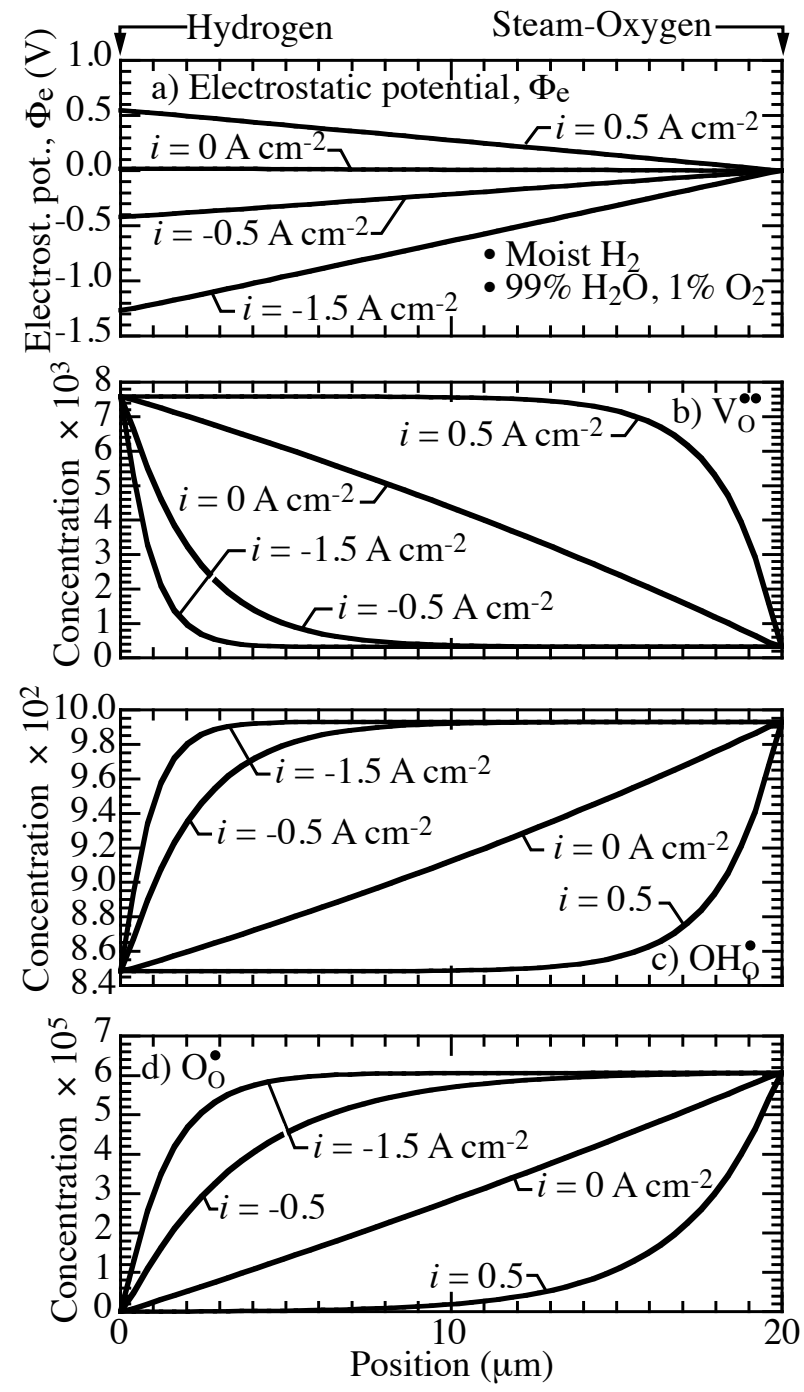

Figure 12: Profiles of electric potential and defect concentrations (formula unit) through the electrolyte membrane at four current densities: $-1.5,-0.5,0.0$ and $0.5 \mathrm{~A} \mathrm{~cm}^{-2}$. The operating temperature is $600{ }^{\circ} \mathrm{C}$. The gas composition is $97 \% \mathrm{H}_{2}$ and $3 \% \mathrm{H}_{2} \mathrm{O}$ on the hydrogen side and $99 \% \mathrm{H}_{2} \mathrm{O}$ and $1 \% \mathrm{O}_{2}$ on the steam-oxygen side.

side as the fuel-cell current density increases. Fig. 12d shows that the polaron concentration and its gradient near the hydrogen side is essentially 


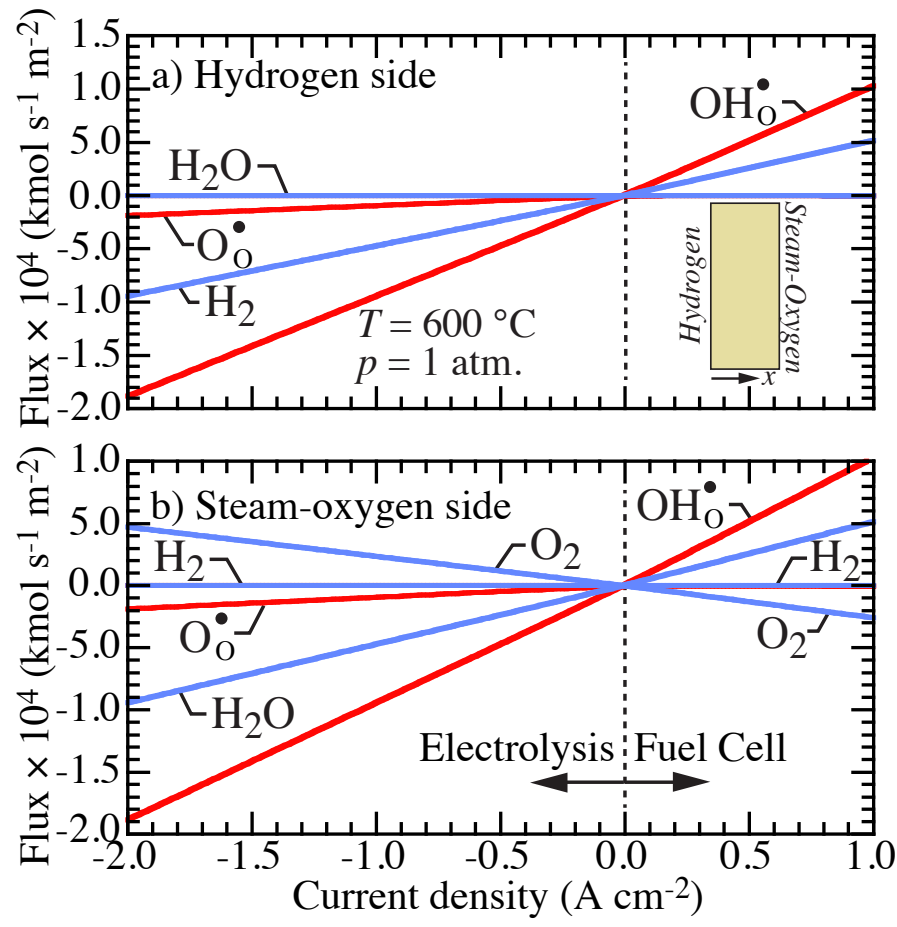

Figure 13: Fluxes of charged defects and gas-phase species at the electrode-electrolyte interfaces as functions of current density. The operating temperature is $600{ }^{\circ} \mathrm{C}$. The gas composition is $97 \% \mathrm{H}_{2}$ and $3 \% \mathrm{H}_{2} \mathrm{O}$ on the hydrogen side, and $1 \% \mathrm{O}_{2}$ and $99 \% \mathrm{H}_{2} \mathrm{O}$ on the steam-oxygen side.

zero at $i=0.5 \mathrm{~A} \mathrm{~cm}^{-2}$. Therefore, as shown on the right-hand side (fuel-cell mode) of Fig. 13, the $\mathrm{O}_{\mathrm{O}}^{\bullet}$ transport flux is negligible and resulting charge flux from $\mathrm{O}_{\mathrm{O}}^{\bullet}$ transport also becomes negligible at high operating current density. The Nernst-Planck flux (Eq. 28) has two terms-diffusion and migration. When the concentration gradient vanishes, the diffusion contribution vanishes. When the concentration itself vanishes, the migration contribution vanishes. Thus, from Fig. $12 \mathrm{~d}$ at $i=0.5 \mathrm{~A} \mathrm{~cm}^{-2}$ is is evident that the $\mathrm{O}_{\mathrm{O}}^{\bullet}$ transport flux must vanish. Because of the negligible losses associated with 
$\mathrm{O}_{\mathrm{O}}^{\bullet}$, the fuel-cell Faraday efficiency achieves nearly unity at high operating current in fuel-cell mode.

Consider now the electrolysis-mode operation. Fig. 12a shows that $\Delta \Phi_{\mathrm{e}} \approx$ $0.42 \mathrm{~V}$ at $i=-0.5 \mathrm{~A} \mathrm{~cm}^{-2}$ and $\Delta \Phi_{\mathrm{e}} \approx 1.27 \mathrm{~V}$ at $i=-1.5 \mathrm{~A} \mathrm{~cm}^{-2}$. Because of the electrostatic potential at the steam-oxygen side is higher than it is at the hydrogen side, the defects are driven toward the hydrogen side (Fig. 12). Under these electrolysis conditions, the $\mathrm{O}_{\mathrm{O}}^{\bullet}$ concentration through the electrolyte membrane is not close to zero, and a large $\mathrm{O}_{\mathrm{O}}^{\bullet}$ concentration gradient is formed near to the hydrogen side as the imposed current density increases. Therefore, the $\mathrm{O}_{\mathrm{O}}^{\bullet}$ flux increases as the electrolysis current density increases (Fig. 13). The $\mathrm{O}_{\mathrm{O}}^{\bullet}$ transport causes a loss of the Faradaic efficiency (Fig. 11).

In electrolysis mode $(i<0)$, Fig. 11 shows that the Faradaic efficiency decreases below zero in the regions around open-circuit. Independent of any imposed current density, the BZY10 acts as a hydrogen-separation membrane. At open-circuit, there is a net flux of protons from the hydrogen side toward the steam-oxygen side. This behavior is more evident at higher temperatures (cf., Fig. 7) than that at lower temperature (cf., Fig. 13). In electrolysis mode, the objective is the transport protons from the steam-oxygen side toward the hydrogen side. This is just the opposite from the direction of the pressure-driven membrane flux. Thus, the imposed electrolysis current density must be sufficiently high as to overcome the counter flux associated with the gas-phase chemical-potential gradient across the membrane.

In a practical protonic-ceramic electrolysis cell, depending on the steam flow rate, oxygen can accumulate on the steam side. Thus, it is interesting to 


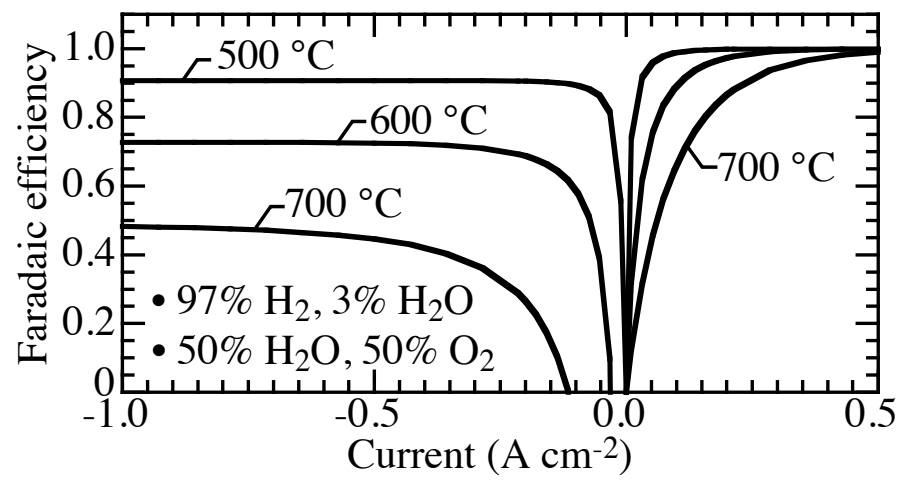

Figure 14: Faradaic efficiencies as function of current density. The gas composition is set to represent electrolysis operation, but with significant oxygen accumulation on the steam side. The gas compositions are $97 \% \mathrm{H}_{2}$ and $3 \% \mathrm{H}_{2} \mathrm{O}$ on the cathode (positive electrode) side and $50 \% \mathrm{O}_{2}$ and $50 \% \mathrm{H}_{2} \mathrm{O}$ on the anode (negative electrode) side. The total pressure is atmospheric.

consider the effect of oxygen concentration on the cell performance. Figure 14 shows the predicted Faradaic efficiency for a cell with $50 \% \mathrm{O}_{2}$ and $50 \% \mathrm{H}_{2} \mathrm{O}$ on the steam side. Comparing with Fig. 10, it is evident that increased oxygen concentration on the steam side significantly decreases the Faradaic efficiency, especially at higher temperatures. In fuel-cell model, however, the Faradiac efficiency is only weakly affected by the oxygen concentration.

These results suggest that a material such as BZY10 is likely to perform well in fuel-cell mode. However, performance in electrolysis model is likely to be less effective. The performance differences are attributed to the fact that BZY10 has p-type conductivity in the form of the O-site polarons. Although required to maintain charge neutrality, the polaron transport represents a deleterious loss mechanism. However, as discussed in the previous paragraphs, the $\mathrm{O}_{\mathrm{O}}^{\bullet}$ transport is largely suppressed in fuel-cell mode. On the 
contrary, $\mathrm{O}_{\mathrm{O}}^{\bullet}$ transport is active in electrolysis mode, representing a significant efficiency loss.

\section{Summary and conclusions}

A Nernst-Planck-Poisson (NPP) model has been developed to evaluate polarization behavior within mixed-conducting ceramic electrolyte membranes. By neglecting all activation and concentration overpotentials, the analysis focuses specifically on the defect transport within the membranes. Although the theory and modeling approaches are generally applicable, the present study considers BZY10, for which a complete self-consistent set of thermodynamic and transport properties is available. The model is exercised in fuel-cell mode and electrolysis mode. Results reveal quantitative polarization behaviors as functions of temperature and imposed current density. Operating cell potential, including open-circuit potential, depend strongly on operating conditions. With mixed-conducting membranes, the open-circuit potential is always lower that the Nernst potential that is typically evaluate for single-ion-conducting membranes such as YSZ. Unlike the singleconducting membranes, where the open-circuit potential can be evaluated in a straightforward way from gas composition, predicting open-circuit potential in mixed conductors requires a more sophisticated model, such as the one presented here. The results suggest that protonic-ceramic mixed conductors with $p$-type electronic conductivity are likely to perform well as fuel-cell membranes, but not as well as electrolyzer membranes. 


\section{Acknowledgements}

This research was supported by the Office of Naval Research via grant N00014-12-1-0201. This research has benefitted from recent insightful discussions with Drs. Hiroshige Matsumoto (Kyushu University), Rotraut Merkle (MPI, Stuttgart), and Mogens Mogensen (RISO). We gratefully acknowledge ongoing collaborations on protonic ceramics and fuel cells with Profs. Sandrine Ricote, Ryan O'Hayre, Greg Jackson, Neal Sullivan (CSM), and Dr. Grover Coors (CoorsTek).

\section{References}

[1] K.D. Kreuer. Proton-conducting oxides. Annu. Rev. Mater. Res., 33:333-359, 2003.

[2] E. Fabbri, L. Bi, D. Pergolesi, and E. Traversa. Towards the next generation of solid oxide fuel cells operating below $600{ }^{\circ} \mathrm{C}$ with chemically stable proton-conducting electrolytes. Adv. Mater., 24:195-208, 2012.

[3] L. Bi, S. Boulfrad, and E. Traversa. Steam electrolysis by solid oxide electrolysis cells (SOECs) with proton-conducting oxides. Chem. Soc. Rev., 43:8255-8270, 2014.

[4] C. Duan, J. Tong, M. Shang, S. Nikodemski, M. Sanders, S. Ricote, A. Almansoori, and R. O'Hayre. Readily processed protonic ceramic fuel cells with high performance at low temperatures. Science, DOI: 10.1126/science.aab3987, 2015. 
[5] E. Fabbri, D. Pergolesia, and E. Traversaa. Materials challenges toward proton-conducting oxide fuel cells: a critical review. Chem. Soc. Rev., 39:4355-4369, 2010.

[6] S.V. Bhide and A.V. Virkar. Stability of $\mathrm{BaCeO}_{3}$-based proton conductors in water-containing atmospheres. J. Electrochem. Soc., 146:20382044, 1999.

[7] E. Fabbri, L. Bi, H. Tanaka, D. Pergolesi, and E. Traversa. Chemically stable Pr and Y co-doped barium zirconate electrolytes with high proton conductivity for intermediate-temperature solid oxide fuel cells. Adv. Funct. Mater., 21:158-166, 2011.

[8] K.H. Ryu and S.M. Haile. Chemical stability and proton conductivity of doped $\mathrm{BaCeO}_{3}-\mathrm{BaZrO}_{3}$ solid solutions. Chem. Mater., 125:355-367, 1999.

[9] Y. Yamazaki, R. Hernandez-Sanchez, and S.M. Haile. High total proton conductivity in large-grained yttrium-doped barium zirconate. Chem. Mater., 21:2755-2762, 2009.

[10] Y. Okumura, Y. Nose, J. Katayama, and T. Uda. High performance protonic ceramic fuel cells with acid-etched surfaces. J. Electrochem. Soc., 158:B1067-B1071, 2011.

[11] N. Nasani, D. Ramasamy, A.D. Brandão, A.A. Yaremchenko, and D.P. Fagg. The impact of porosity, $p_{\mathrm{H}_{2}}$ and $p_{\mathrm{H}_{2} \mathrm{O}}$ on the polarisation resistance of Ni-BaZr ${ }_{0.85} \mathrm{Y}_{0.15} \mathrm{O}_{3-\delta}$ cermet anodes for protonic ceramic fuel cells (PCFCs). Inter. J. Hydrogen Energy, 39:21231-21241, 2014. 
[12] L. Bi, E. Fabbri, Z. Sun, and E. Traversa. $\mathrm{BaZr}_{0.8} \mathrm{Y}_{0.2} \mathrm{O}_{3-\delta^{-}} \mathrm{NiO}$ composite anodic powders for proton-conducting SOFCs prepared by a combustion method. J. Electrochem. Soc., 158:B797-B803, 2011.

[13] A. Magrasó, M.L. Fontaine, R. Haugsrud, and T. Norby. Hydrogen oxidation kinetics and performance of $\mathrm{Ni}-\mathrm{LaNbO}_{4}$ cermet anodes for proton conducting SOFCs. J. Electrochem. Soc., 164:F373-F379, 2014.

[14] S. Akoshima, M. Oishi, K. Yashiro, K. Sato, and J. Mizusaki. Reaction kinetics on platinum electrode/yttrium-doped barium cerate interface under $\mathrm{H}_{2}-\mathrm{H}_{2} \mathrm{O}$ atmosphere. Solid State Ionics, 181:240-248, 2010.

[15] N. Bonanos and M. Mogensen. $\mathrm{H}_{2}$ oxidation at the interface $\mathrm{Ni} / \mathrm{Sr}_{0.995} \mathrm{Ce}_{0.95} \mathrm{Y}_{0.95} \mathrm{O}_{2.975}$. Solid State Ionics, 97:483-488, 1997.

[16] D. Kek, N. Bonanos, M. Mogensen, and S. Pejovnik. Effect of electrode material on the oxidation of $\mathrm{H}_{2}$ at the metal- $\mathrm{Sr}_{0.995} \mathrm{Ce}_{0.95} \mathrm{Y}_{0.05} \mathrm{O}_{2.970}$ interface. Solid State Ionics, 131:249-259, 2000.

[17] H. Shimada, X. Li, A. Hagiwara, and M. Ihara. Proton-conducting solid oxide fuel cells with yttrium-doped barium zirconate for direct methane operation. J. Electrochem. Soc., 160:F597-F607, 2013.

[18] A. Lapina, C. Chatzichristodoulou, P. Holtappels, and M. Mogensen. Composite $\mathrm{Fe}-\mathrm{BaCe}_{0.2} \mathrm{Zr}_{0.6} \mathrm{Y}_{0.2} \mathrm{O}_{2.9}$ anodes for proton conductor fuel cells. J. Electrochem. Soc., 161:F833-F837, 2014.

[19] W. Sun, M. Liu, S. Feng, W. Liu, and H.C. Parka nd M. Liu. Hydrogen oxidation at the $\mathrm{Pt}-\mathrm{BaZr}_{0.1} \mathrm{Ce}_{0.7} \mathrm{Y}_{0.1} \mathrm{Yb}_{0.1} \mathrm{O}_{3-\delta}(\mathrm{BCZYYb})$ interface. Phys. Chem. Chem. Phys., 15:3820-3826, 2013. 
[20] F. He, T. Wu, R. Peng, and C. Xia. Cathode reaction models and performance analysis of $\mathrm{Sm}_{0.5} \mathrm{Sr}_{0.5} \mathrm{CoO}_{3-\delta}-\mathrm{BaCe}_{0.8} \mathrm{Sm}_{0.2} \mathrm{O}_{3-\delta}$ composite cathode for solid oxide fuel cells with proton conducting electrolyte. $J$. Power Sources, 194:263-268, 2009.

[21] L. Zhao, B. He, J. Gu, F. Liu, X. Chu, and C. Xia. Reaction model for cathodes cooperated with oxygen-ion conductors for solid oxide fuel cells using proton-conducting electrolytes. Inter. J. Hydrogen Energy, $37: 548-554,2012$.

[22] R. Peng, T. Wu, W. Liu, X. Liu, and G. Meng. Cathode processes and materials for solid oxide fuel cells with proton conductors as electrolytes. J. Mater. Chem., 20:6218-6225, 2010.

[23] D. Poetzsch, R. Merkle, and J. Maier. Oxygen reduction at dense thinfilm microelectrodes on a proton-conducting electrolyte. I. Considerations on reaction mechanism and electronic leakage effects. J. Electrochem. Soc., 162:F939-F950, 2015.

[24] R. Strandbakke, V.A. Cherepanov, A. Yu. Zuev, D.S. Tsvetkov, C. Argirusis, G. Sourkouni, S. Prunte, and T. Norby. Gd- and Pr-based double perovskite cobaltites as oxygen electrodes for proton ceramic fuel cells and electrolyser cells. Solid State Ionics, 278:120-132, 2015.

[25] C. Yang, X. Zhang, H. Zhao, Y. Shen, Z. Du, and C. Zhang. Electrochemical properties of $\mathrm{BaZr}_{0.1} \mathrm{Ce}_{0.7} \mathrm{Y}_{0.1} \mathrm{Yb}_{0.1} \mathrm{O}_{3-\delta}-\mathrm{Nd}_{1.95} \mathrm{NiO}_{4+\delta}$ composite cathode for protonic ceramic fuel cells. Inter. J. Hydrogen Energy, 40:2800-2807, 2015. 
[26] H. Zhu, S. Ricote, W.G. Coors, and R.J. Kee. Interpreting equilibriumconductivity and conductivity-relaxation measurements to establish thermodynamic and transport properties for multiple charged defect conducting ceramics. Faraday Discussions, DOI: 10.1039/c5fd00012b, 2015.

[27] I. Riess. Theoretical treatment of the transport equations for electrons and ions in a mixed conductor. J. Electrochem. Soc., 128:2077-2018, 1981.

[28] I. Riess. The possible use of mixed ionic electronic conductors instead of electrolytes in fuel cells. Solid State Ionics, 52:127-134, 1992.

[29] M. Liu. Distributions of charged defects in mixed ionic-electronic conductors. I. General equations for homogeneous mixed ionic-electronic conductors. J. Electrochem. Soc., 144:1813-1834, 1997.

[30] W. Lai and S.M. Haile. Electrochemical impedance spectroscopy of mixed conductors under a chemical potential gradient: a case study of Pt-SDC-BSCF. Phys. Chem. Chem. Phys., 10:865-883, 2008.

[31] R.J. Kee, H. Zhu, B.W. Hildenbrand, E. Vøllestad, M.D. Sanders, and R.P. O'Hayre. Modeling the steady-state and transient response or polarized and non-polarized proton-conducting doped-perovskite membranes. J. Electrochem. Soc., 160:F290-F300, 2013.

[32] M. Liu. Equivalent circuit approximation to porous mixed-conducting oxygen electrodes in solid-state cells. J. Electrochem. Soc., 145:142-154, 1998. 
657

[33] G.W. Coffey, L.R. Pederson, and P.C. Rieke. Competition between bulk and surface pathways in mixed ionic electronic conducting oxygen electrodes. J. Electrochem. Soc., 150:A1139-A1151, 2003.

[34] E. Vøllestad, H. Zhu, and R.J. Kee. Interpretation of defect and gasphase fluxes through mixed-conducting ceramics using Nernst-PlanckPoisson and integral formulations. J. Electrochem. Soc., 161:F114-F124, 2014 .

[35] H. Cohen and J.W. Cooley. The numerical solution of the timedependent Nernst-Planck equations. Biophys. J., 5:145-162, 1965. 